\title{
Diversité bioclimatique et potentiel de diversification des cultures : un atout pour le développement agricole de l'Argentine
}

\author{
CM Baldy', CM Rebella 2 \\ 'LECSA - INRA, Place Viala, 34060 Montpellier, France \\ 2 INTA Instituto Agua y Clima, 1712 Castelar, Buenos Aires, Argentine
}

(Reçu le ?, accepté le ?)

\begin{abstract}
Résumé - Ce travail cherche à évaluer le potentiel de diversification des cultures en Argentine par rapport à la diversité des milieux naturels du pays.

La première partie décrit la diversité des bioclimats en Argentine et les met en relation avec la répartition géographique actuelle des principales productions agricoles : un potentiel agronomique important existe, encore mal mis en valeur. L'inadéquation entre zonation bioclimatique et zones de production est flagrante dans certains cas. La mauvaise gestion actuelle du milieu naturel contribue à l'accélération de la dégradation des terres cultivées, aussi bien que des terres de parcours.

La deuxième partie passe en revue diverses méthodes culturales (dont l'intérêt a déjà été mis en évidence), qui pourraient être mises en œuvre par les agriculteurs afin de réduire les pertes de fertilité, l'érosion (hydrique comme éolienne) afin de maintenir, voire d'améliorer ainsi les rendements. On insiste sur les problèmes liés au surpâturage généralisé.

La troisième partie constitue le cœur de l'étude : elle analyse, pour chaque grande zone bioclimatique, comment diffuser plus largement diverses productions (végétales et animales), dont l'adaptation aux bioclimats argentins est déjà prouvée.

On verra enfin que cette diversification des productions, basée sur une meilleure utilisation des ressources bioclimatiques du pays, est possible à condition que ses modalités d'application soient analysées par la recherche agronomique argentine : ces modalités sont à prendre en compte dans les programmes de développement nationaux.
\end{abstract}

Argentine / bioclimat / protection des sols / élevage / culture nouvelle

Summary - Bioclimatic diversity and crop diversification potential: a key to the agricultural development of Argentina. This paper attempts to evaluate the potential for diversification of crops in Argentina in relation to the diversity of natural environments of the country.

The first section describes the diversity of the bioclimates in Argentina: climate (figs 1-6); geological survey (fig 7); natural vegetation (fig 8), main crops (figs 9 and 10), livestock breeds (fig 12), agro-industrial production (figs 11 and 12): an important agronomic potential exists, which is not yet well developed. The second section presents cropping techniques that could be used to reduce fertility losses - a phenomen on linked to present inadequate methods and to water (fig 14) and wind erosion - and to allow the maintenance or improvement of yields. We analyze methods to spread the knowledge of tillage techniques, crop successions etc, allowing a better soil protection throughout the year, and finally how to reintroduce fodder crops and permanent pastures. Particular emphasis is laid on problems due to overgrazing. The third section deals with the heart of the study: we recommend a choice of crops, fruit trees and livestock breads already introduced in the main climatic areas of Argentina, but on a small scale. The introduction on a larger scale could diversify national production (fig 15). In conclusion, it is thought that an important diversification of agricultural production based on better use of the bioclimatic potential could be obtained in the short term, and that this requires an adequate study to be made by the agricultural research service in Argentina which should be taken into account in national development programmes.

Argentina / bioclimate / new crop / husbandry / soil protection 


\section{INTRODUCTION}

$L^{\prime}$ 'Argentine s'étend de $22^{\circ}$ à $55^{\circ}$ de latitude sud, et entre $54^{\circ}$ et $73^{\circ}$ de longitude ouest, ce qui se traduit par une très grande diversité bioclimatique et pédologique; sa superficie continentale est de 2,8 millions de $\mathrm{km}^{2}$. La population, 32 millions d'habitants environ, soit moins de 12 habitants par $\mathrm{km}^{2}$, estimation de 1988, est très irrégulièrement répartie. Près de 12 millions peuplent le Grand Buenos Aires et $89 \%$ vivent dans des "centres urbains" de plus de 2000 habitants. Mais on ne compte que $0,5 \mathrm{~h} / \mathrm{km}^{2}$ à SantaCruz (Sud de la Patagonie), contre $43,5 \mathrm{~h} / \mathrm{km}^{2}$ dans la province de Tucumán. L'Argentine est nettement moins peuplée que la plupart des autres pays latino-américains.

L'Atlantique sud limite le pays à l'est, et les Andes font frontière avec le Chili à l'ouest : l'Aconcagua culmine à $6960 \mathrm{~m}$, près de Mendoza.

Le pays possède d'importantes réserves de pétrole et de gaz et de nombreux gisements minéraux dans les Andes. Les sites d'extraction sont d'accès difficile et les transports à longue distance posent des problèmes complexes : les réseaux routier et ferroviaire développés il y a plus d'un siècle pour faciliter l'exportation des produits agricoles sont actuellement obsolètes et les voies d'eau formées par le Paraná et ses affluents et l'Uruguay, largement utilisées jusqu'au milieu du $X X^{\ominus}$ siècle ne correspondent plus au tonnage croissant des navires : l'envasement des chenaux et des ports fluviaux réduisent leur intérêt économique. Le réseau d'aéroports est bien développé, mais l'absence de chaine du froid, et l'inadaptation des structures de réception du fret, réduisent les possibilités d'exportation de produits agricoles périssables.

Près d'un million de kilomètres carrés se situent en climats humide ou subhumide sur des sols de lœss ou d'alluvions fluviatiles (ensemble chaquéen, pampéen et mésopotamien). Le reste du pays (près de 2 millions de $\mathrm{km}^{2}$ ) est semiaride ou aride. La barrière climatique due aux Andes provoque une forte aridité entre les 25 et $40^{\circ} \mathrm{S}$ dans l'ouest du pays. Du fait de son altitude, l'Altiplano andin du nord-ouest est également peu arrosé. La Patagonie constitue une vaste zone steppique aride et venteuse, à l'exception de sa frange andine plus humide.

Le pays possède un potentiel de production considérable, en matières d'élevage, d'agriculture et de forêts. Les exportations reposent sur- tout sur les productions agricoles : chaque année, le choix de celles-ci par les agriculteurs dépend du prix international des produits au moment des semis.

Nous chercherons à montrer que la diversification des cultures peut jouer localement un rôle considérable et réduire régionalement le carcan actuel des monoproductions (ou plutôt des oligoproductions). En 1988, les statistiques douanières argentines (citées par le Bulletin économique de l'ambassade de France) indiquent que les exportations de fruits et légumes $(528000 \mathrm{t})$ ont dépassé, en valeur financière comme en tonnage, celles de la viande bovine (287 $000 \mathrm{t})$, ce qui montre le potentiel de développement de l'Argentine dans ce secteur, alors que ces "cultures nouvelles» occupent actuellement à peine plus de 500000 ha.

Après avoir situé les grandes aires pédoclimatiques et phytosociologiques du pays, on verra que la mise en relation de la diversité bioclimatique de l'Argentine et de la diversité géographique des productions agricoles actuelles met en évidence l'inadéquation de certaines pratiques à leur milieu naturel, ce qui contribue à dégrader les ressources naturelles.

Une meilleure répartition et une diversification raisonnée des cultures (et des élevages) permettraient de mieux participer aux grands courants commerciaux mondiaux : ainsi, une meilleure gestion du potentiel de production de fruits et légumes à contre-saison permettrait de mieux approvisionner les grands consommateurs de l'hémisphère nord, et représenterait un avantage économique certain, d'origine géographique.

\section{DIVERSITÉ BIOCLIMATIQUE DE L'ARGENTINE ET DIVERSITÉ DES PRODUCTIONS AGRICOLES}

\section{Zones climatiques}

La figure 1 situe les grandes zones bioclimatiques, les stations météorologiques présentées en diagrammes, et les isohyètes annuels moyens. Les pluies sont généralement à dominante estivale dans l'ensemble du pays (fig 2 ad). Elles présentent de très fortes variabilités interannuelle et mensuelle : la figure $2 \mathrm{e}$ analyse cette variabilité pour la station de Castelar, près de Buenos Aires, dans la Pampa humide. 


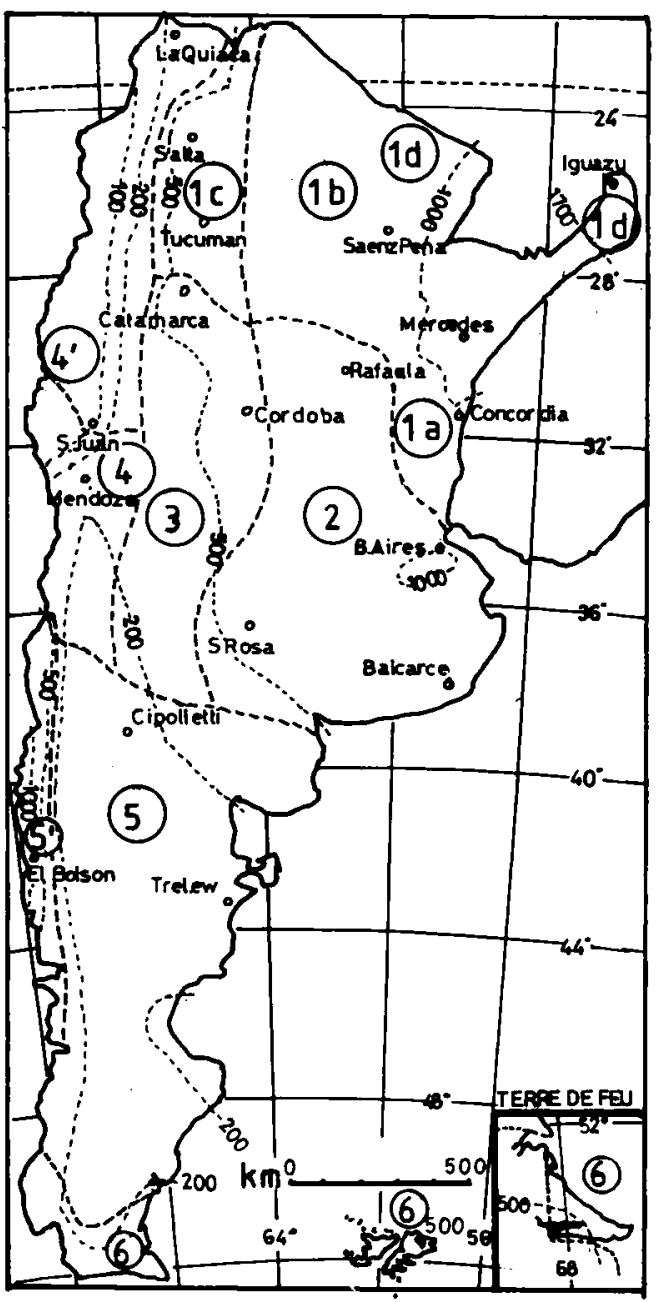

Fig 1. Pluies annuelles moyennes et régions naturelles principales d'Argentine. - - - Isohyètes. Grandes régions naturelles : 1) NE : Mésopotamie, Chaco, est de Tucumán, Formosa et Misiones; 2) Pampa : Buenos Aires, Santa Fé, est de Córdoba; 3) Zone semi-aride de transition : est de Catamarca et La Rioja, ouest de Córdoba et la Pampa, San Luis; 4) Cuyo : Mendoza, San Juan, ouest de La Rioja; 4), Andes arides et Altiplano du NW : ouest de Catamarca, de Tucumán, de Salta et de Jujuy; 5) Patagonie : Rio Negro, Chubut, Santa Cruz; 5), Patagonie andine humide; 6) Terre de Feu et îles australes.

Durant l'été, les précipitations sont souvent orageuses et localisées, ce qui agit fortement sur la variabilité spatiale des rendements à l'intérieur d'une même zone. Leur importance varie d'une année à l'autre, comme aussi l'intensité de la sècheresse hivernale : celle-ci limite le rendement des cultures d'hiver, quand les pluies d'automne n'ont pu reconstituer complètement les réserves des sols (Defina, 1973; Defina et Ravelo, 1973; Hall et al, 1988; Magrin, 1990).

La pluviosité diminue d'est en ouest dans l'ensemble du pays, à l'exception de la frange formée au sud du $40^{\circ} \mathrm{S}$ en Patagonie andine. Elle atteint $2000 \mathrm{~mm}$ dans la province de Misiones,
$300 \mathrm{~mm}$ en Mésopotamie, et $1000 \mathrm{~mm}$ dans la Pampa ondulée, à l'ouest de Buenos Aires. A titre d'exemple, la figure 3 (Hall et al, 1988) analyse la répartition saisonnière des pluies dans l'ensemble pampéen et mésopotamien :

\section{Pluies d'hiver (fig 3a)}

A l'est, les cultures sont assez bien alimentées en eau; moins bien à l'ouest.

\section{Les pluies de printemps (fig 3b)}

Elles sont plus importantes que les pluies d'hiver. On observera la rotation des isohyètes vers le SE-NW, sauf dans la Mésopotamie (région située entre les rios Paraná et Uruguay).

\section{Les isohyètes des pluies d'été (fig 3c)}

Elles sont orientées SE-NW. Elles sont plus fortes et souvent orageuses dans le NE de la zone (Pampa ondulée, Mésopotamie et province de Santa-Fé). Leurs variations interannuelles influent fortement sur les rendements des cultures d'été.

\section{Les pluies d'automne (fig 3d)}

Comme les pluies d'hiver, elles ont un gradient est-ouest marqué. Ces précipitations jouent un rôle fondamental dans l'agriculture pampéenne : les années où elles sont trop abondantes, elles peuvent compromettre les récoltes d'été et les semis d'automne; les automnes secs, pour leur part, réduisent les chances des cultures d'hiver. Souvent orageuses, les pluies d'automne peuvent être très érosives sur des sols nus ou de jeunes semis.

L'importance des précipitations est inférieure à $50 \mathrm{~mm} / \mathrm{an}$ dans certaines zones des Andes dans l'ouest des provinces de Mendoza, San Juan, la Rioja et Catamarca; elle est de l'ordre de $300 \mathrm{~mm} / \mathrm{an}$ sur l'Altiplano Salto-Jujenien (contre plus de $800 \mathrm{~mm} / a n$ à Salta, située en Piémont), et dans presque toute la Patagonie (fig 2c).

Dans les Andes de Patagonie, en altitude, les précipitations dépassent $2000 \mathrm{~mm}$, à la frontière du Chili; elles sont à dominante hivernale, avec une sécheresse estivale marquée : c'est la seule région d'Argentine à climat de type méditerranéen frais (fig 2a). 

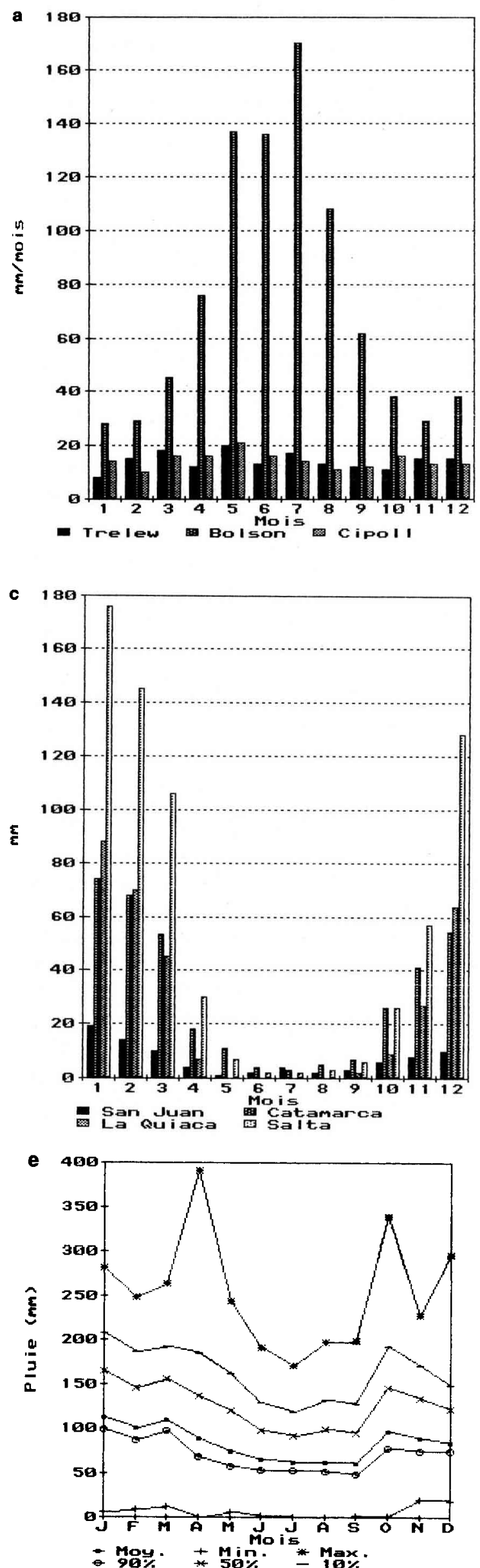
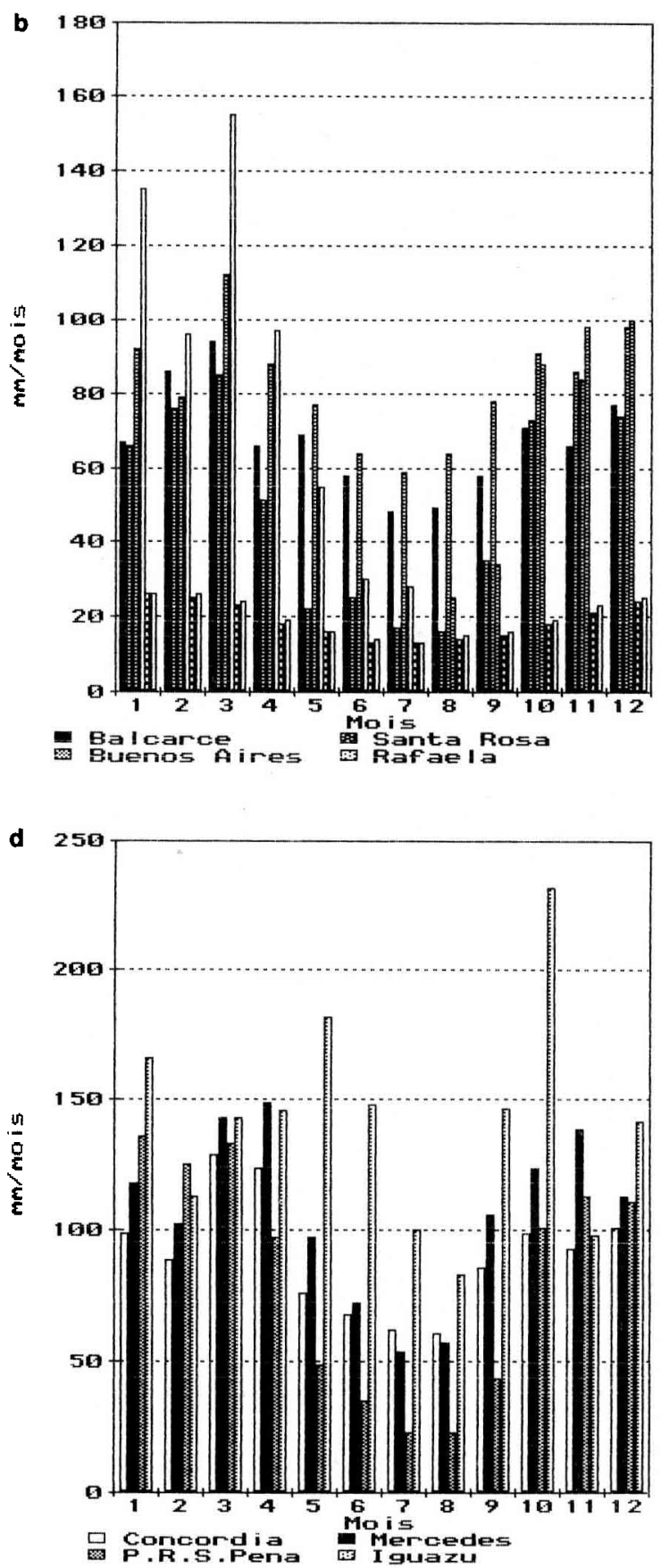

Fig 2. Pluies moyennes mensuelles de quelques stations représentatives des grandes zones climatiques d'Argentine. a : Patagonie; b : Pampa; c : Zones andines et pré-andines; $\mathbf{d}$ : Mésopotamie, Chaco et Misiones; e : Etude fréquentielle des pluies mensuelles sur 30 ans (1951-1982) à Castelar (Buenos Aires). Fréquences classées par déciles, moyennes et extrêmes observés (Conti et Santamaria, 1987).

Caractéristiques bioclimatiques des stations météorologiques sélectionnées : a. Patagonie - Situations arides : Trelew (littoral); Cipolletti (haute vallée du Rio Negro) - Situation à climat méditerranéen humide des Andes de Patagonie : El Bolsón. b. Situations de plaine - Climats de la Pampa : ouest semiaride : Santa Rosa; sud à influence atlantique : Balcarce; Nord ouest - Pampa ondulée : Buenos Aires, Climat du Chaco oriental : Presidencia R Saenz Peña; Climats subtropicaux : Mésopotamie : Concordia, Mercedes de Corrientes; Misiones : Iguazu. c. Zones préandine et andine - Zone aride du Cuyo : San Juan - Préandes semi-arides centrales - Catamarca - Préandes subtropicales humides du Nord - Salta; Altiplano subtropical : La Quiaca. 

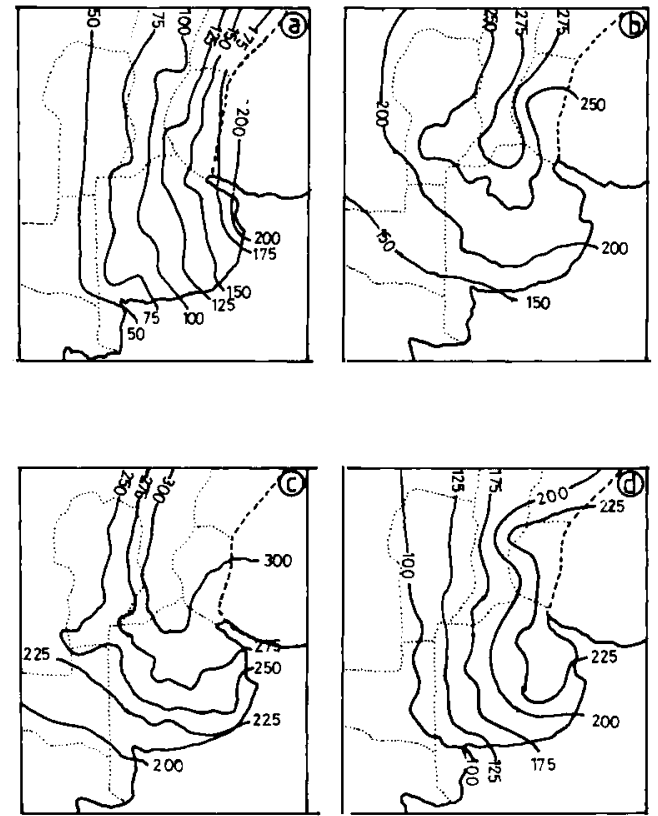

Fig 3. Pluviométries saisonnières dans la Pampa (d'après Hall et al, 1988). a. Pluies d'hiver (juin à août); b. Pluies de printemps (septembre à novembre); c. Pluies d'été (décembre à février); d. Pluies d'automne (mars à mai).

La figure 4 retrace les isothermes moyens de janvier (été) et juillet (hiver). Leurs orientations diffèrent, en raison de l'affrontement permanent des masses d'air tropical et polaire sur l'Argentine. La figure 5 a-c présente l'évolution mensuelle des températures des stations retenues; la figure $5 d$ exprime les durées des risques de gelées sous abri pour quelques stations : aucun point d'Argentine n'est à l'abri de la gelée.

La figure 6 a-c présente les évapotranspirations potentielles calculées par la méthode de Penman, modifiée par Frere et Popov (1979). Elles varient beaucoup entre stations pour une même zone bioclimatique : ceci est lié à la force locale des vents, à la situation par rapport aux influences atlantiques ou andines, et donc à l'humidité relative de l'air et à l'intensité du rayonnement solaire incident, fonction lui-même de l'ennuagement local.

En résumé, les climats d'Argentine vont du subtropical à hiver frais (au nord du $26^{\circ} \mathrm{S}$ ) au polaire (en Antarctide) : ils permettent d'envisager l'introduction ou le développement d'un grand nombre de cultures (annuelles ou pérennes) et d'élevages.

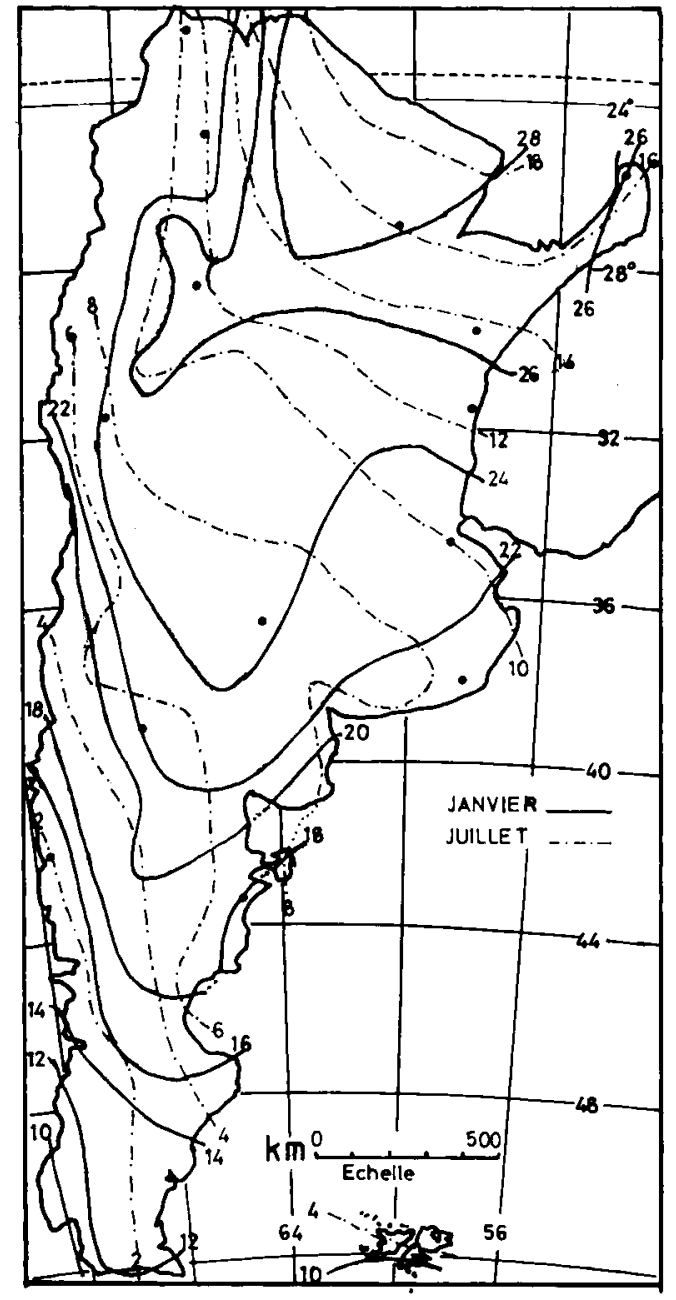

Fig 4. Températures moyennes de janvier et de juillet en Argentine.

\section{Les grandes régions bioclimatiques}

La figure 7 (d'après Daus, 1987) situe les grandes unités structurales géologiques d'Argentine, qui se repercutent sur les sols. Sous une homogénéité apparente, ces derniers présentent de fortes différences de valeur potentielle. Ainsi, dans la Pampa ondulée, un horizon B induré limite sur plus de $100000 \mathrm{~km}^{2}$ la vitesse d'infiltration des pluies et le passage en profondeur des racines (Hall et al, 1988).

Des problèmes analogues se rencontrent dans d'autres zones : au sud de la Province de Buenos Aires, un tuf existe sur des dizaines de milliers de $\mathrm{km}^{2}$, horizon d'accumulation du calcaire (tosca en espagnol) (Suero et Garay, 1978); sur le "bouclier brésilien», au nord-est, des milliers de $\mathrm{km}^{2}$ de sols ferralitiques indurés 
a
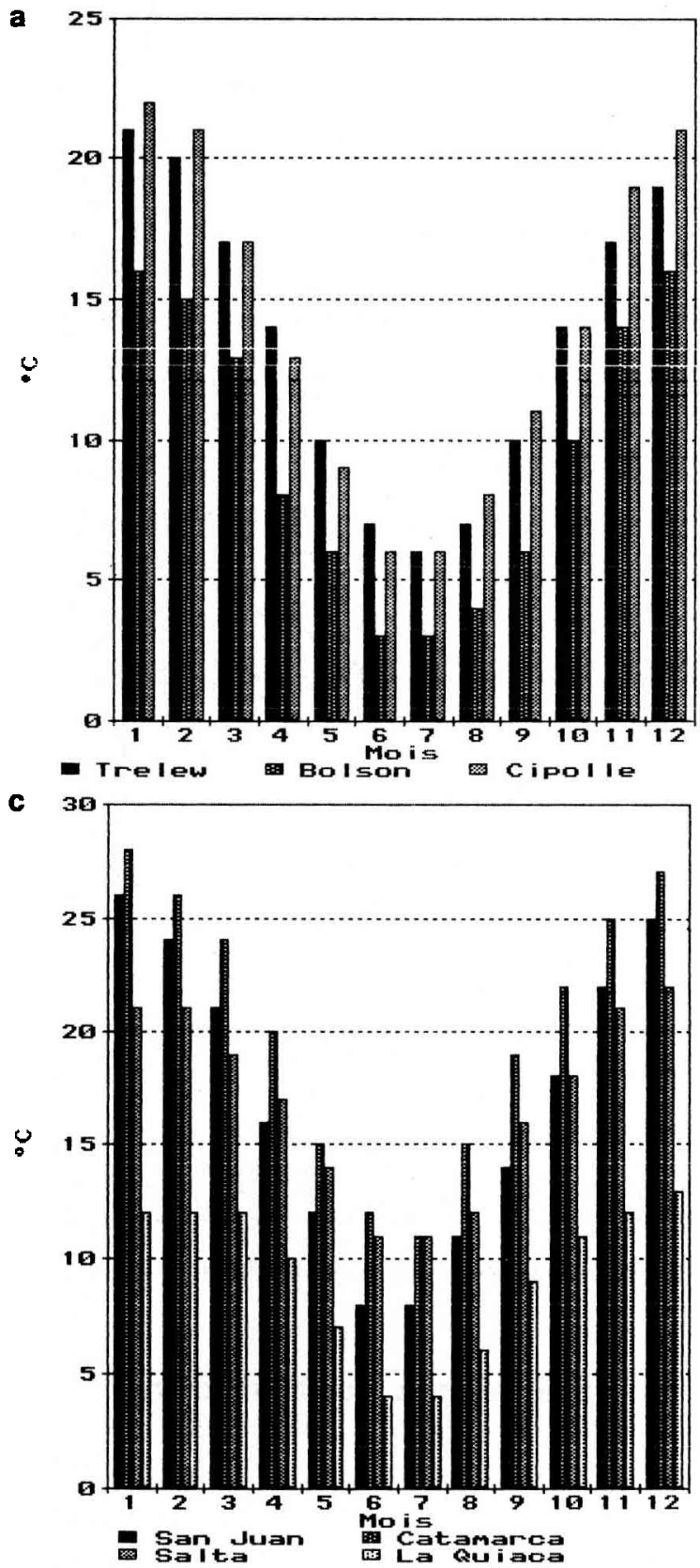

b

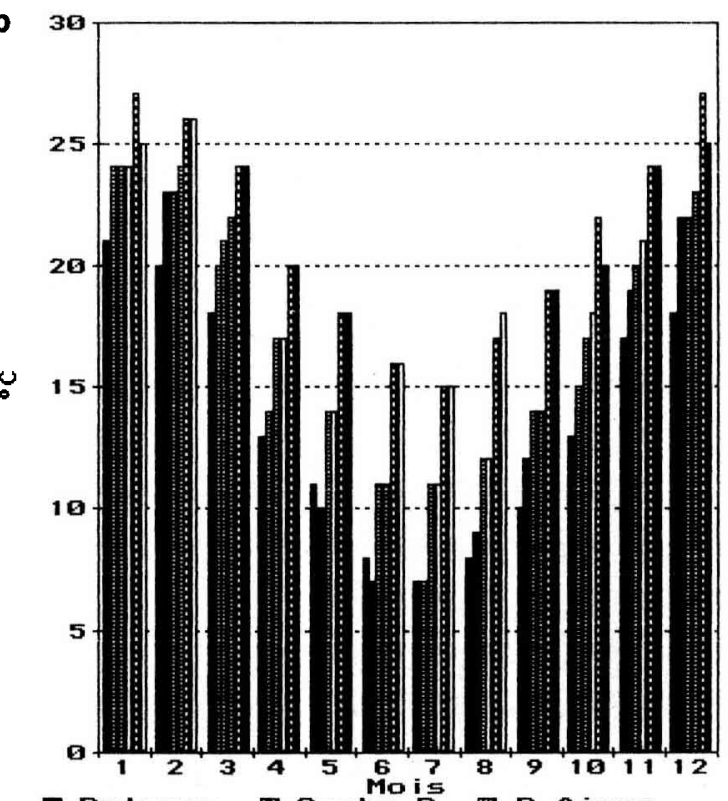

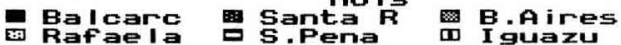

d

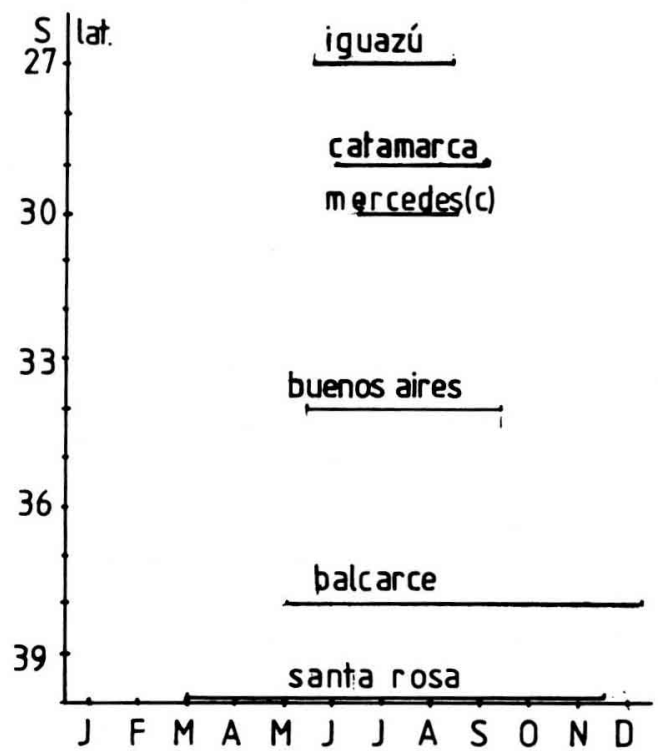

Fig 5. Températures moyennes mensuelles pour ces mêmes zones. a. Patagonie; b. Pampa et Nord-Est; $\mathbf{c}$. Andes et pré-andes. d. Durée des risques de gelée sous abri pour quelques stations de plaine.

Caractéristiques bioclimatiques des stations météorologiques sélectionnées : a. patagonie - situations arides : Trelew (littoral); Cipo/letti (haute vallée du Rio Negro) - Situation à climat méditerranéen humide des Andes de Patagonie : El Bolsón. b. Situations de plaine - Climats de la Pampa : ouest semi-aride : Santa Rosa; sud à influence atlantique : Balcarce; nord ouest, Pampa ondulée : Buenos Aires - Climat du Chaco oriental : Presidencia R Saenz Peña - Climats subtropicaux, Mésopotamie : Concordia, Mercedes de Corrientes; Misiones : Iguazu. c. Zones préandine et andine - Zone aride du Cuyo : San Juan - Préandes semi-arides centrales : Catamarca - Préandes subtropicales humides du Nord : Salta - Altiplano subtropical : La Quiaca.

en profondeur sont très lessivés par les fortes pluies dès que la végétation naturelle est perturbée.

Sur plus de $500000 \mathrm{~km}^{2}$, de la Pampa, de la Mésopotamie et du Chaco, existent des nappes phréatiques très superficielles. On y observe aussi la formation de mares et de lagunes plus ou moins persistantes pendant les périodes pluvieuses ainsi que l'endoréisme de vastes ré- gions, en l'absence de toute possibilité d'écoulement rapide des eaux de pluies. Les faibles pentes et l'existence de zones de subsidence littorales expliquent ces formations, qui favorisent l'accumulation de sel et nuisent aux pâturages et aux cultures. Elles sont indiquées en grisé sur la figure 8.

Toutes les cultures subtropicales et tempérées sont envisageables ou existent déjà, de la canne 

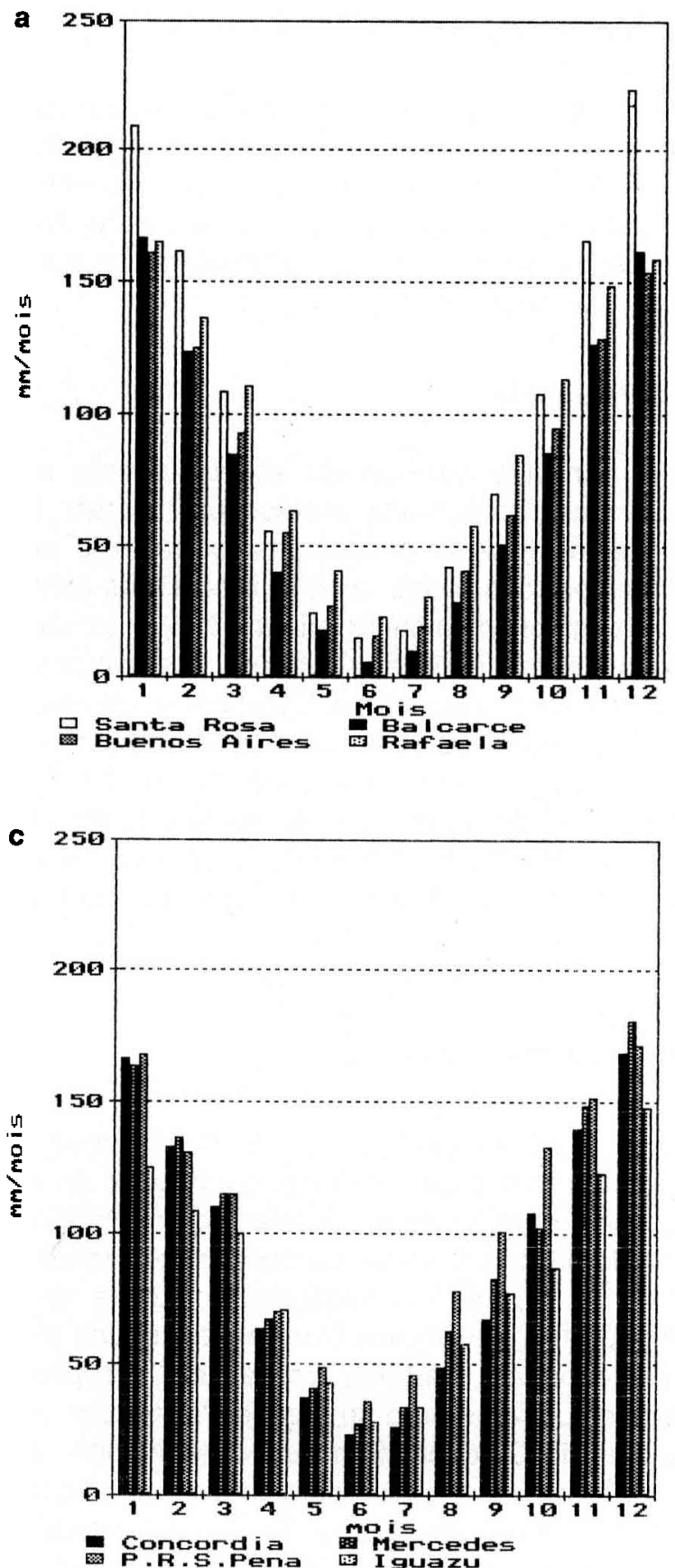

à sucre à Tucumán, aux pommes de la haute vallée du Rio Negro et au houblon des Andes de Patagonie.

L'augmentation de la population et la croissance de sa consommation dépassent actuellement celles des productions principales, à l'exception notable du soja (Burgos, 1983).

\section{La Pampa}

Elle occupe la quasi-totalité de la province de Buenos Aires, et une grande partie de celles de

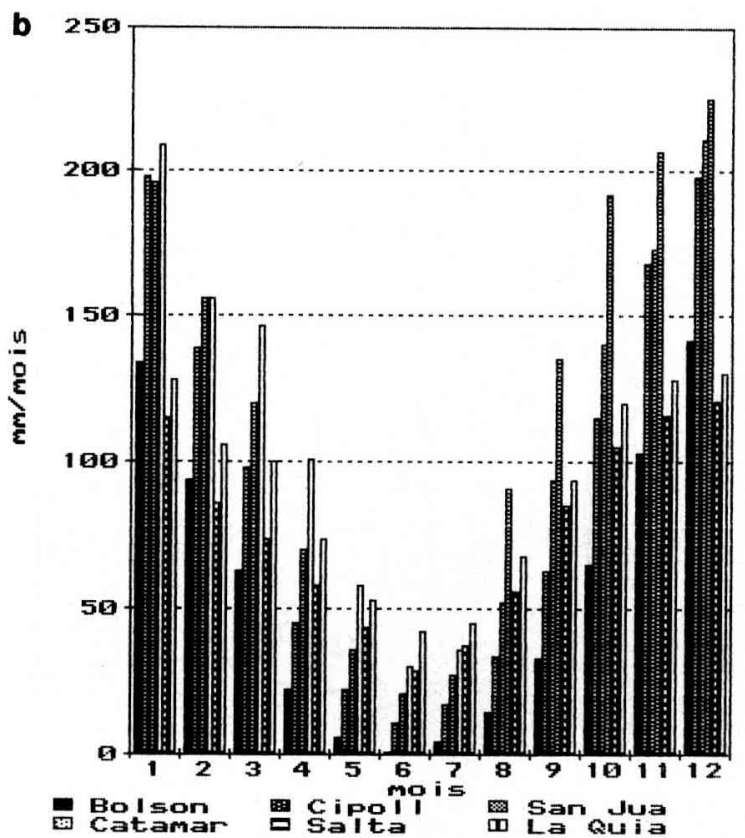

Fig 6. Evapotranspirations potentielles moyennes mensuelles pour ces mêmes stations. a : Pampa; $\mathbf{b}$ : Nord-Est; c: Zones andines et Patagonie.

la Pampa, Córdoba et Santa Fé, soit 450000 $\mathrm{km}^{2}$. On a vu sur la figure 1 que la pluviosité passe de $1000 \mathrm{~mm}$ au nord-est (Buenos Aires, Rafaela), à moins de $500 \mathrm{~mm}$ à Santa Rosa, à l'est de la province de la Pampa. On a vu sur la figure 3 que l'orientation des isohyètes y varie beaucoup d'une saison à l'autre, ce qui se traduit d'est en ouest par des potentiels de production très différents des cultures d'hiver (blé et orge surtout). La Pampa ondulée est la région la plus fertile du pays; située au nord de la province de Buenos Aires et au sud de celles de Córdoba et de Santa Fé, elle couvre 150000 $\mathrm{km}^{2}$ environ.

\section{Le Chaco}

C'est une plaine d'origine alluviale d'environ $300000 \mathrm{~km}^{2}$, due aux affluents andins du Paraná, principalement les Rios Bermejo et Pilcomayo; elle présente un gradient pluviométrique marqué d'est en ouest (Saenz Peña, 1000 mm; 


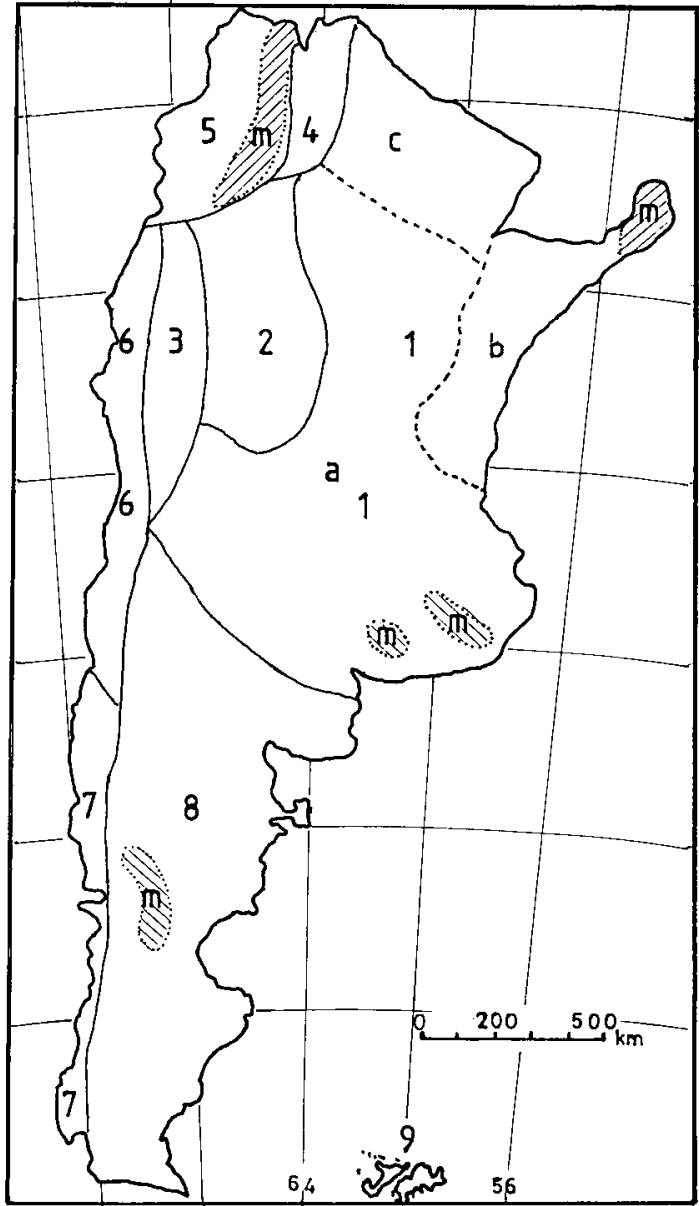

Fig 7. Grandes unités structurales géologiques (d'après Daus, 1987) : 1) Régions de sédimentation récente sur base cristalline, appartenant au massif de Brasilia, (a) plaine pampéenne, (m) Reliefs anciens inclus; (b) Mésopotamie; (c) Chaco; 2) Montagnes pampéennes (Córdoba, Tucumán, etc.); 3) Précordillère; 4) Montagnes subandines; 5) Puna et cordons orientaux (altiplano); 6) Géosynclinal andin; 7) Sections andines de Patagonie et de Terre de Feu; 8) Patagonie et reliefs patagons; 9 ) lles malouines.

Santiago del Estero, $500 \mathrm{~mm}$ ), avec une pluviométrie essentiellement estivale.

\section{La Mésopotamie}

Elle couvre près de $200000 \mathrm{~km}^{2}$. Cette plaine en grande partie alluviale, située entre les fleuves Paraná et Uruguay, est limitée par le vieux massif du «bouclier brésilien" à l'est et au nord. Les pluies, réparties sur toute l'année, atteignent $1300 \mathrm{~mm}$ à Mercedes de Corrientes. Au nord-est, la province de Misiones, située sur le "bouclier brésilien", est la plus arrosée (1700 $\mathrm{mm}$ à lguazú). C'est une région d'élevage (bovin et ovin), et la zone essentielle de la riziculture; Misiones produit la yerba maté argentine, le thé, et d'autres cultures tropicales.

\section{La région aride du Cuyo (San Juan)}

Située à l'ouest du pays (provinces de Mendoza et de San Juan), elle concentre sa production agricole sur un ensemble de vastes périmètres irrigués où dominent la vigne, les arbres fruitiers, les oliviers et les cultures maraîchères. Le climat $y$ est très continental.

\section{La Patagonie}

Elle constitue au Sud, un espace encore peu aménagé : moins d'un mouton par hectare exploite les maigres ressources fourragères produites par des pluies rares et irrégulières (généralement en quantité inférieure à $300 \mathrm{~mm} / \mathrm{an}$ ), sous un ciel souvent nuageux. Les troupeaux subissent un hiver long et rigoureux et des vents presque permanents. Au nord de la Patagonie, la vallée du Rio Negro (Cipolletti, fig 2a, 5a, 6a), constitue une vaste oasis tempérée de plus de $200 \mathrm{~km}$ de long sur $1-5 \mathrm{~km}$ de large, avec de très importantes productions de pommes, poires, prunes, etc.

\section{La végétation naturelle}

La figure 8 (d'après Daus, 1987), distingue 15 grandes formations phytogéographiques en Argentine, outre le territoire antarctique). Près des $2 / 3$ du pays sont arides ou semi-arides (zones 5 , $11,12,13,15)$. La végétation naturelle de la Pampa (6), grenier actuel du pays, est une prairie dépourvue d'arbres, à quelques exceptions locales près. Le nord du pays et l'ouest des provinces de Córdoba, San Luis et la Pampa sont forestiers, avec une dominance de légumineuses : Prosopis, Acacia, Celtis, mais aussi de très nombreuses autres familles: Schinopsis, $T i$ puana, Tabebuiaipa, Peltophora, Alnus, etc.

Les forêts à Araucarias et Nothofagus dominent dans les Andes de Patagonie (Capitanelli, 1988).

\section{Principales productions agricoles actuelles}

Le mot "agricole" sera pris ici dans son sens large : il recouvre les activités agricoles, l'élevage, les pâturages naturels et les plantations forestières.

La figure 9 a-d présente l'évolution des surfaces et des productions des principales cultures 


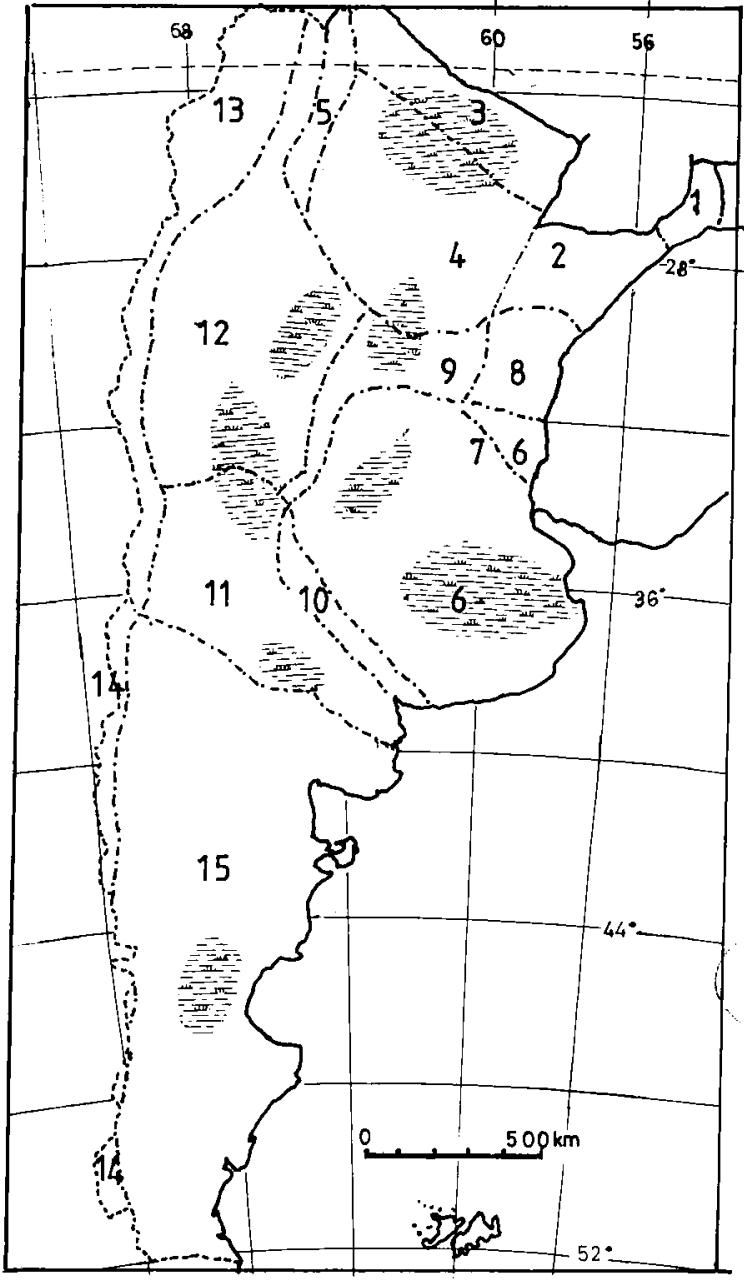

Fig 8. Grandes formations phytogéographiques d'Argentine (d'après Daus, 1987). 1) Forêt de Misiones; 2) Forêts-galeries et forêts-parcs de Corrientes; 3) Forêt de Formosa; 4) Boisements du Chaco, et parcs marginaux; 5) Forêts montagnardes sub-tropicales; 6) Steppe herbacée de la Pampa sensu-stricto; 7) forêts littorales de La Plata et du Dela; 8) Forêt d'Entre Rios; 9) Forêts de Santa Fé et Córdoba; 10) Boisements semi-arides pampéens; 11) Steppe arbustive de la Pampa occidentale; 12) Formations des sierras et campos; 13) Steppes de la Puna andine; 14) Forêts de la cordillère patagone; 15) Steppes arbustives de la Patagonie; [: : :] zones endoréiques ou mal drainées.

annuelles pendant les 10 dernières années : les productions de sorgho fluctuent beaucoup, celles de blé sont assez stables, et celles de maïs décroissent, alors que celles de soja croissent : cette dernière culture a été introduite dans le pays il y a 20 ans seulement.

La figure 10 situe les principales productions agricoles actuelles sur le territoire argentin.

Toutes les données citées proviennent des statistiques du secrétariat d'état à l'Agriculture, ou des Annales de la Société rurale (1989).

\section{Cultures annuelles}

Les cultures d'hiver couvrent environ dix millions d'hectares. II s'agit surtout de blé tendre (et d'un peu de blé dur), d'orge, d'avoine, et de lin oléagineux. On notera leur stabilité, à l'exception du lin qui a beaucoup diminué, en raison de la mévente sur le marché mondial.

Les cultures d'été occupent dix autres millions d'hectares. II s'agit surtout de soja, de maïs, de tournesol, d'arachide et de cotonnier (fig 9d). Ces productions sont orientées essentiellement vers l'exportation. Le développement du soja paraît entraîner la décroissance d'autres cultures (sorgho et arachide).

Les cultures fourragères de sorgho, fétuques, dactyles, panicum, stylosanthes, etc. sont utilisées en pâturage direct ou plus rarement en foin. La luzerne a été à la base de la mise en culture de l'Argentine à la fin du XIXe siècle (Saenz Quesada, 1980) : après avoir atteint $8,5.10^{6}$ ha en 1922 , elle n'en occupe plus que $2.10^{6}$ en 1980 , mais reste la culture fourragère principale de la Pampa. Ces productions sont destinées surtout à l'alimentation des bovins.

\section{Cultures fruitières}

Les fruitiers tempérés se rencontrent surtout dans la vallée du Rio Negro, au nord de la Patagonie, autour de Buenos Aires, et au sud de Mendoza. Ils couvrent plus de 300000 ha au total.

Les fruitiers subtropicaux sont importants aussi : les agrumes couvrent plus de $10^{5}$ ha : citronniers de Tucumán; orangers, pomelos, mandariniers d'Entre Rios, Corrientes, Buenos Aires et Santa Fé. Les bananiers sont localisés à Salta et Jujuy surtout; ils représentent 7500 ha. La vigne de table se développe actuellement à Mendoza, San Juan, La Rioja, et Catamarca. Le kiwi s'étend au nord du Grand Buenos Aires.

Toutes ces cultures, souvent conduites à l'irrigation, sont en pleine expansion grâce à l'amélioration actuelle des moyens de transports.

Quelques cultures arbustives industrielles ont pris de l'importance mais dépendent beaucoup des possibilités de consommation locale (maté), ou d'exportation (tung, thé, vigne) : théier, yerba maté (Ilex paraguensis) et tung (Aleurites fordii) à Misiones, olivier à La Rioja, Catamarca, Mendoza. Chacune de ces cultures occupe de 10 à 50000 ha environ. 

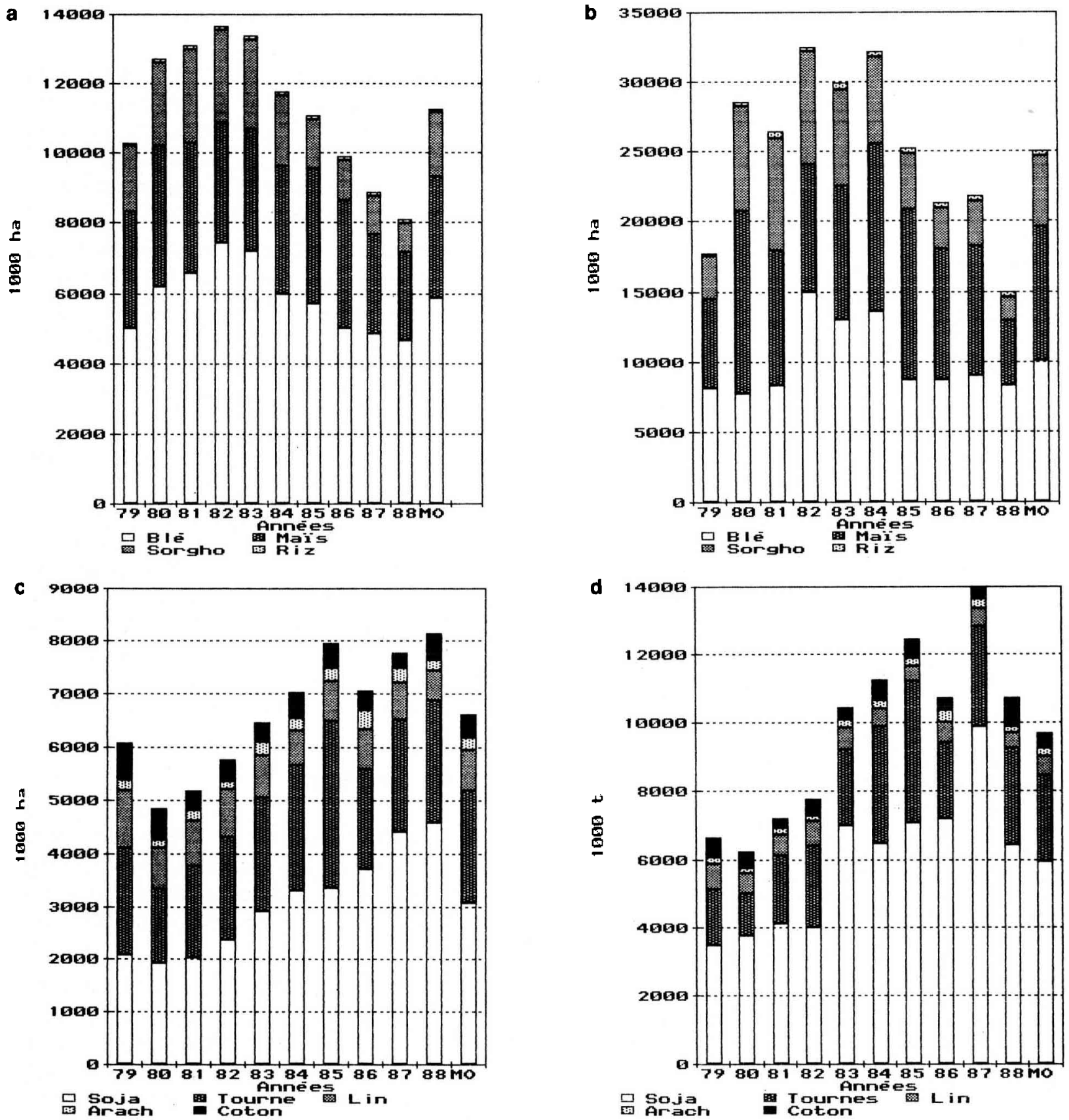

Fig 9. Evolution des surfaces et des productions des principales cultures en Argentine de 1979 à 1988 et moyenne (MO) de la décennie. a) surfaces de céréales (x $\left.10^{3} \mathrm{ha}\right)$; b) productions de céréales $\left(\times 10^{3} \mathrm{t}\right)$; c) surfaces d'oléagineux et de cotonnier $\left(x 10^{3} \mathrm{ha}\right)$; d) productions d'oléagineux et de coton-graine $\left(\times 10^{3} \mathrm{t}\right)$.

La vigne de cuve (à Mendoza, San Juan et Salta surtout), couvre encore une superficie de 275000 ha, et produit $36.10^{6}$ de quintaux de raisin, entièrement à l'irrigation; la politique d'arrachage actuelle réduit les surfaces, et l'introduction de cépages de qualité diminue les rendements.

La canne à sucre s'étend sur plus de 350000 ha et produit $10^{6}$ tan de sucre. Ressource essentielle de Tucumán, elle est importante aussi à Salta et Jujuy. Elle pose problème, en raison des capacités limitées d'absorption par le marché intérieur et des difficultés d'exportation liées au bas prix mondial du sucre (fig 11). Après quelques années de régression, le cotonnier reprend de l'importance dans le Chaco (fig 9c, $d$ et 12).

\section{Cultures maraîchères}

Toutes les cultures maraîchères de plein champ et sous abri (à contre-saison), et les principales fleurs à couper existent à plus ou moins grande 


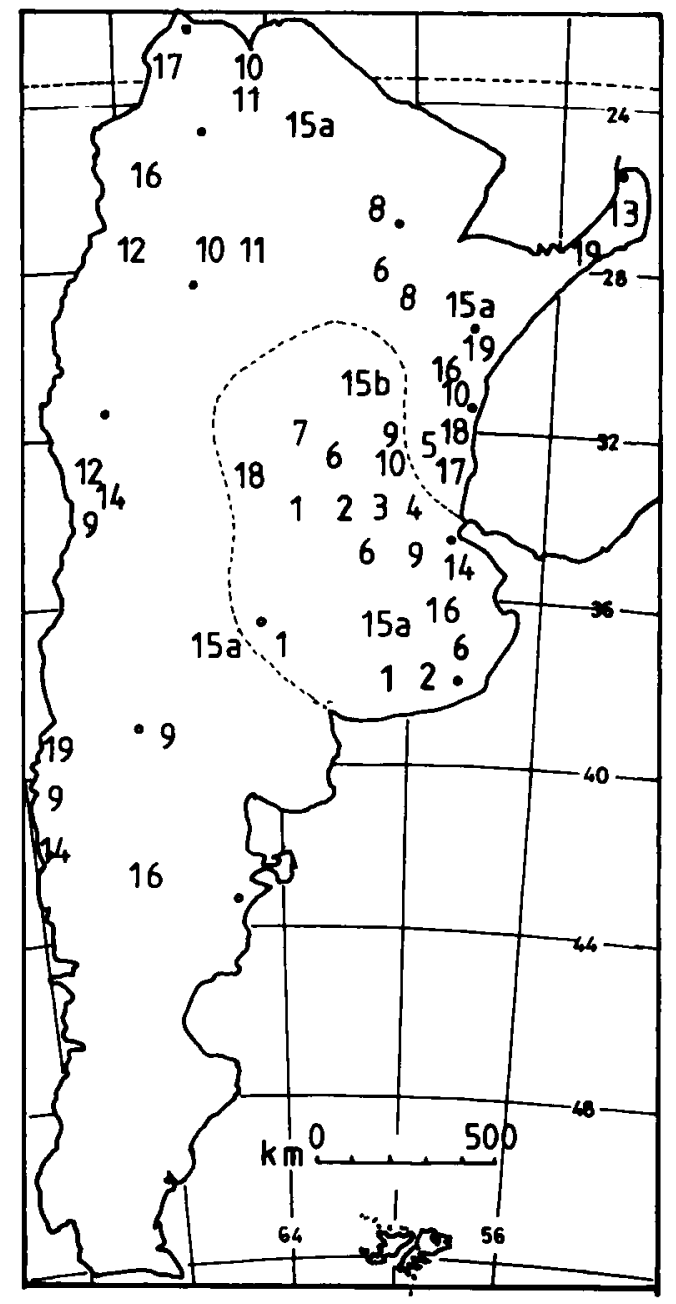

Fig 10. Répartition des principales productions agricoles actuelles en Argentine : 1) ble; 2) maiis; 3) soja; 4) sorgho; 5) lin; 6) tournesol; 7) arachide; 8) cotonnier; 9) fruitiers tempérés; 10) Citrus; 11) canne à sucre; 12) vigne; 13) maté et thé; 14) maraîchage; 15) bovins : 15a) à viande; 15b) laitiers; 16) ovins; 17) élevages divers; 18) apiculture; 19) plantations forestières.

échelle en Argentine; il s'agit souvent de variétés anciennes, ou de semences importées, d'Europe surtout.

\section{Elevages}

La figure 13 présente l'évolution des productions de viande de boeuf, mouton et porc, au cours des 10 dernières années, et la figure 11 celle de la production laitière pendant la même période.

Les bovins comptent actuellement $45.10^{6}$ têtes environ. La production nationale de viande bovine avoisine $3.10^{6} \mathrm{t}$, dont $15 \%$ sont exportés actuellement. Leur élevage se concentre du sud de la Pampa au sud du Chaco; dans les zones arides tempérées, on rencontre la "race créole", très rustique. Des élevages existent en Patago-

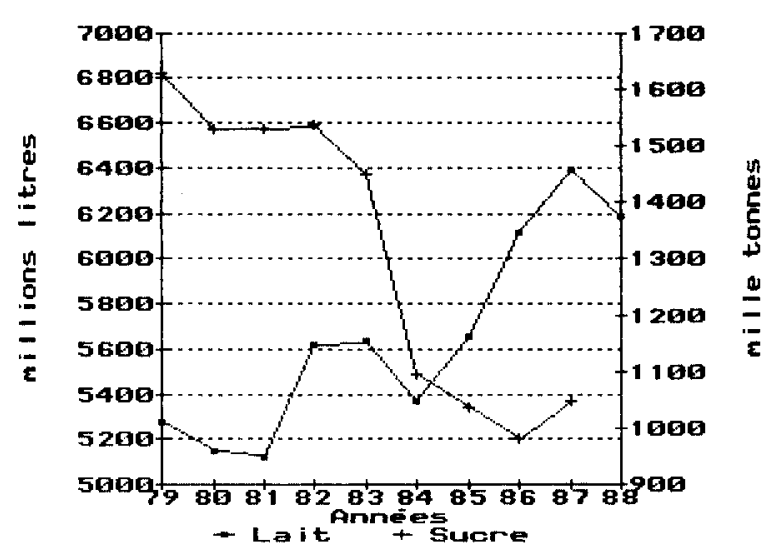

Fig 11. Productions de lait et de sucre en Argentine durant la décennie 1979-1988. Noter la baisser de la production sucrière à partir de 1984, et la croissance de la production laitière.

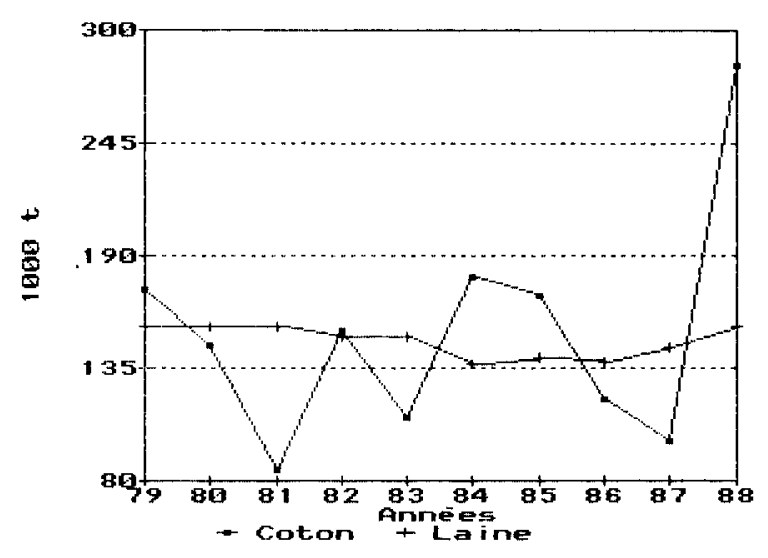

Fig 12. Productions de coton-fibre et de laine pour la décennie 1979-1988. Noter la grande variabilité interannuelle des productions de coton-fibre, et la stabilité de la production lainière.

nie, là ou l'on a implanté des prairies irriguées. Zébus et croisements (bovin $x$ zébu) se localisent en climats subtropicaux : Chaco, Formosa, Corrientes, Salta, Jujuy.

Les ovins se situent dans la dépression du Salado (fig 10), en Entre Rios et à Corrientes, sur les Altiplanos andins, et surtout en Patagonie. Avec $22.10^{6}$ têtes en 1988 , ils représentent moins du tiers du cheptel existant au début du siècle. Leur production de laine varie relativement peu d'une année à l'autre (fig 12).

Les caprins sont élevés en zones marginales, de même que les lamas, localisés sur l'Altiplano aride.

Les élevages porcins se situent surtout autour des grandes villes, et dans les zones laitières.

II existe des élevages industriels importants de poules (œufs et chair), de dindes, et de lapins angoras (pour le poil). 
L'apiculture, assez importante dans les provinces de Buenos Aires, la Pampa, Córdoba et Entre Rios, est plus marginale ailleurs, pour des raisons de difficultés de collecte et de transport; plus de 25000 t de miel sont exportées chaque année, notamment vers l'Allemagne.

\section{Plantations forestières}

II existe $35.10^{6}$ ha de forêts naturelles en Argentine, dont $20.10^{6}$ ha en zones aride ou semiaride : une grande partie des forêts sèches est plus ou moins fortement dégradée par le pâturage désordonné des bovins et les feux de forêt. Plus de 700000 ha ont été boisés en essences forestières : ce chiffre est à comparer à celui des forêts naturelles; 400000 ha d'Eucalyptus grandis (saligna) ont été implantés en Entre Rios, Corrientes et Misiones sur de vastes surfaces, pour la papeterie surtout. Des boisements comportant d'autres espèces d'eucalyptus se répartissent dans toute la moitié nord de l'Argentine humide et subhumide (jusqu'au $38^{\circ} \mathrm{S}$ ) (CIEF, 1985). Des pins tropicaux sont plantés dans les mêmes zones que les $E$ grandis, mais aussi à Salta et Jujuy, et des Araucarias tropicaux (pins Paraná) à Misiones.

Les peupliers existent un peu dans tout le pays, et en particulier à Mendoza, Neuquén et Rio Negro (vallées irriguées), et dans la Pampa subhumide et humide (avec des saules pleureurs).

Des résineux européens et nord-américains originaires de climats tempérés (pins noirs, Pseudotsuga spp etc) forment de vastes peuplements artificiels dans les zones humides de $\mathrm{Pa}$ tagonie (Bortagaray, 1988).

\section{En conclusion}

Les productions du pays sont assez diversifiées, mais souvent localisées dans des régions limitées, sans que des raisons pédologiques ou bioclimatiques puissent l'expliquer vraiment : les provinces de Chaco, de Formosa et le nord de Santa Fé ont le monopole de la production cotonnière; Tucumàn, Salta et Jujuy, celui de la production sucrière.

Le problème le plus préoccupant est celui de la diminution des pâturages naturels, et de l'augmentation de l'érosion et de la dégradation des terres cultivées. La disparition des prairies naturelles de la Pampa se traduit par la raréfaction de nombreuses graminées autochtones (Stipa, Melica, Aristida).

La production de viande stagne, et son volume exportable diminue : elle est encore considérée dans le pays comme un élément essentiel de la balance des paiements du pays, ce que nient les statistiques d'exportation.

La diversification des productions agricoles et la recherche de marchés à contre-saison pourraient constituer une alternative.

\section{DES MÉTHODES CULTURALES PLUS ÉCONOMES DES SOLS ET QUI EXPLOITENT MIEUX LES RESSOURCES DU CLIMAT}

\section{Méthodes de labour et de rotations des cultures}

Les agronomes argentins cherchent à introduire les notions de rotations, successions, alternance de cultures, et d'agriculture conservative, peu connues encore dans le pays : l'absence de rotations ou même de successions des cultures, et la pratique de la culture dérobée, qui se développe actuellement, sont à l'origine de graves problèmes de conservation de la fertilité des sols (Coscia, 1983; Deybe, 1989).

\section{La conservation à long terme des sols argentins}

Elle paraît chaque année plus menacée : en climats humide et subhumide, les efforts des producteurs portent sur l'augmentation de la production, en appliquant des techniques de "double culture, blé et soja", c'est à dire des cultures dérobées d'été suivant une céréale d'hiver. (Flichman et Deybe, 1987; Moscardi, 1987).

La disparition progressive des prairies naturelles et des matorrals, parcours formés de ligneux à base de légumineuses, la réduction des surfaces de prairies artificielles de luzerne dans les zones climatiquement les plus favorisées, et la quasi-disparition de la jachère, couplées avec le pâturage intensif des chaumes durant l'hiver, réduisent rapidement les taux de matière organique : par rapport à la luzerne, le soja laisse peu de résidus organiques et d'azote dans le sol.

Depuis la généralisation des cultures continues, il y a moins de 30 ans, on observe une réduction permanente des taux de matière organique dans les sols de la Pampa humide (qui 


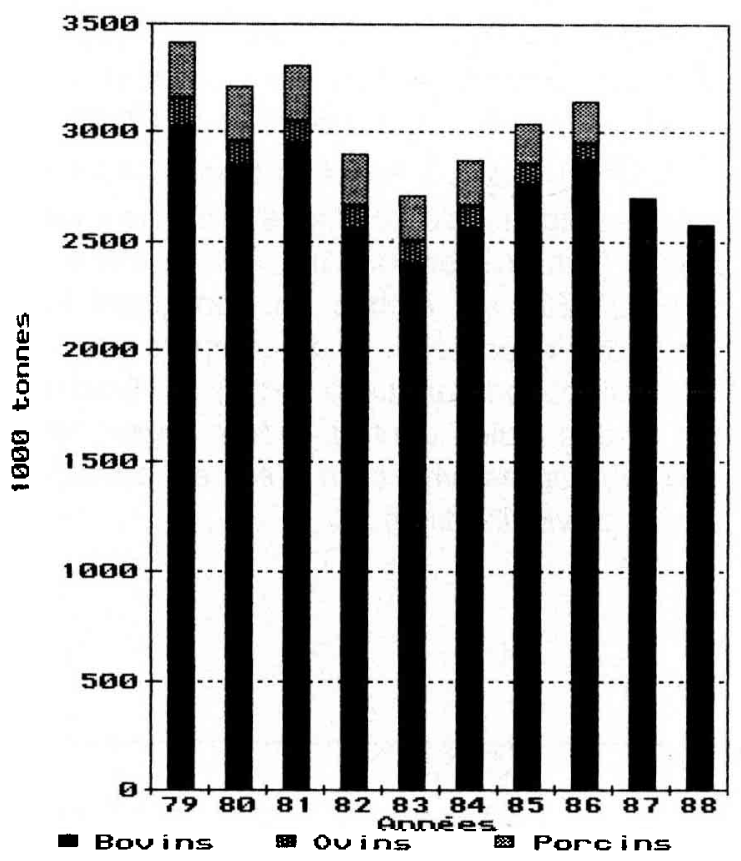

Fig 13. Productions de viandes en Argentine, pour la décennie 1979-1988. Noter la part écrasante de la viande bovine et la décroissance relative de sa production durant la décennie. Les statistiques concernant les viandes ovine et porcine manquent pour les années 1987 et 1988.

produit à elle seule près de la moitié de l'ensemble des céréales et des oléagineux d'Argentine) : ils sont passés de $5 \%$ à moins de 2 en moyenne (Musto, 1979). Elle s'accompagne d'une diminution des capacités réelles de stockage de l'eau par le sol, et d'une péjoration des caractéristiques physiques : l'indice de stabilité structurale a été réduit de 40 à $60 \%$ selon les zones. On considère que $36 \%$ des sols de la Pampa sont plus ou moins gravement érodés (Deybe, 1989; Hall et al, 1988).

Une autre caractéristique de la situation actuelle est la faible utilisation des engrais : $180000 \mathrm{t}$ de fertilisants (NPK), (dont $50000 \mathrm{im}$ portées), ont été épandues sur les $5,4.10^{6}$ ha de blé emblavés durant l'hiver 1989 (c'est-à-dire moins du dixième du niveau moyen français de fertilisation). Les herbicides et divers produits phytosanitaires sont plus largement employés. Cependant, diverses mauvaises herbes (chénopodes, amaranthes, Datura, etc.) résistent aux herbicides courants. On note l'apparition de maladies (Sclerotinia du tournesol, Fusarium du soja, etc.) et d'attaques parasitaires nouvelles (coléoptères parasites des grains, borers du maïs, etc.) (Ballare et al, 1987).

Le système de production spéculatif actuel privilégie chaque année la culture qui se vend le mieux au moment du semis, ce qui explique le développement du soja depuis 15 ans, ou du blé en 1988-1989 : beaucoup d'agriculteurs louent leurs terres à la culture, ou à l'année, et les locataires se préoccupent peu des précédents culturaux : ils cherchent la culture qui aura le meilleur rapport financier, compte tenu de la saison et des prix relatifs (Flichman et Deybe, 1987).

Ce système lié, dans la pampa humide, aux divisions des propriétés après des héritages successifs, freine l'introduction de méthodes culturales améliorées, même si leur intérêt est évident. Heureusement pas généralisé à l'ensemble des exploitations, il se répand du fait des difficultés économiques : dans la province de Buenos Aires, plus de $3.10^{6}$ ha $y$ sont soumis (Hall et al, 1988; Fecic-Prosa, 1988).

\section{Les méthodes de travail du sol}

Les méthodes les plus courantes constituent une autre source de préoccupation : les charrues créent des semelles de labour qui freinent ou bloquent le développement des racines et l'infiltration des pluies en profondeur. Elles provoquent des nappes perchées temporaires, ou au moins des zones de saturation en eau dans le profil du sol après de fortes pluies. Le travail vertical avec des chisels ou autres outils analogues, permet de réduire cette zone indurée (Magrin, 1990).

\section{La fragilité des sols}

Les producteurs en ont peu conscience : seules des méthodes conservatives permettront d'améliorer (voire de sauver) le potentiel de production encore existant. L'idée que Pampa humide, Chaco et Mésopotamie ont des potentiels de production énormes (Daus, 1987) doit être oubliée. La situation est d'autant plus grave que les sols sont plus légers, et plus souvent soumis à des pluies torrentielles (comme dans les parties occidentales de la Pampa et du Chaco) (Hall et al, 1988).

\section{Le maintien du potentiel de production}

Il passe par la réintroduction de cultures fourragères (annuelles ou pérennes, pures ou associant 2 ou plusieurs espèces complémentaires) dans les systèmes de production. Des luzernes, et des prairies temporaires, associant éventuel- 
lement plusieurs graminées à une ou plusieurs légumineuses, sont à encourager. Leur exploitation doit tenir compte du rythme de croissance des pâturages au cours de l'année, afin d'assurer au mieux les besoins quantitatifs et qualitatifs des animaux.

Ces prairies temporaires sont à introduire dans des successions culturales, qui tiennent compte des exigences pédo-climatiques de chaque plante introduite, et des arrière-effets d'une culture sur la suivante.

\section{Conditions de mise en application}

Tout ce qui précède ne peut être appliqué que si des prix agricoles suffisants motivent les producteurs, et dans la mesure où ces derniers acceptent de privilégier le maintien à long terme de la production. On en est loin actuellement.

\section{Les risques d'érosion}

\section{L'érosion hydrique}

Elle constitue le problème le plus préoccupant : trop de sols restent nus pendant les périodes de pluies intenses dues aux conditions climatiques subtropicales dans toute la zone agricole utile d'Argentine. Elles créent des variations très importantes des températures de surface, qui échauffent considérablement les sols nus; les pluies de type orageux, violentes et abondantes, provoquent des écoulements en surface. Après

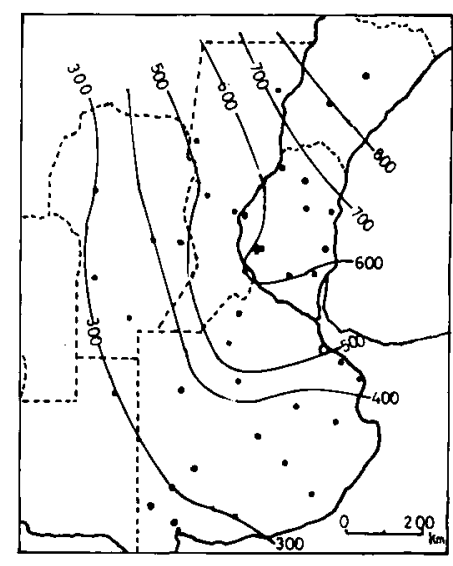

Fig 14. Carte des indices de risque d'érosion hydrique de la Pampa et de la Mésopotamie, selon la formule de Wischmeier (d'après Rojas et Conde, 1980). Les indices de risque (R) sont exprimés en mm/an par rapport à la somme de leurs indices d'érosivité mensuels calculés à partir des pluies du mois et des intensités maximales en $30 \mathrm{~min}$. Les gradients nord-sud et est-ouest sont dus respectivement aux influences tropicales, et à l'éloignement de l'Atlantique. quelques années de pratiques culturales imprudentes, l'érosion est souvent impressionnante (Rojas et Conde, 1980; Scotta et al, 1986).

La figure 14, due à Rojas et Conde (1980) délimite les lignes d'égal risque d'érosion par les pluies (exprimé en $\mathrm{mm} / \mathrm{an}$ ) sur la zone pampéenne. Elle est établie en appliquant la méthode de Wischmeier. Si on compare cette carte aux distributions annuelle (fig 1) et trimestrielle (fig 3) des pluies dans la même région, on voit que leur agressivité croît d'est en ouest, alors que la pluviosité diminue.

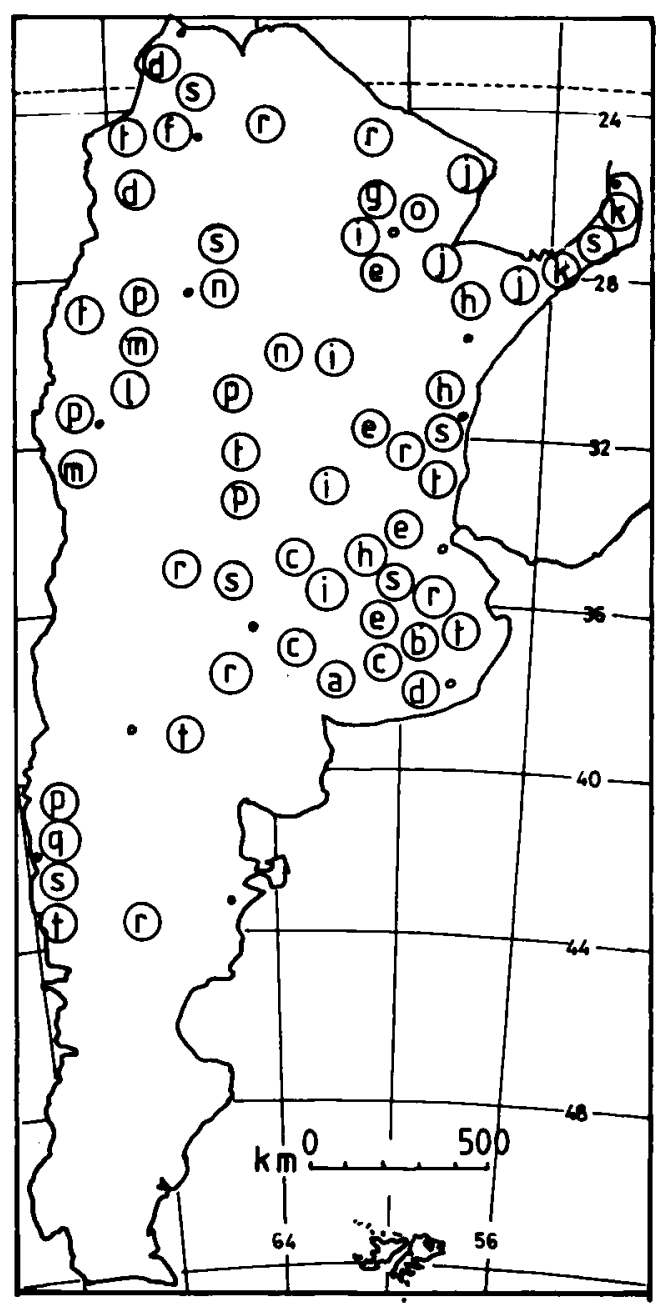

Fig 15. Carte de répartition zonale des principales productions nouvelles proposées. 1) Zones tempérées humides et subhumides : a) colza; b) betteraves; c) lupins; d) pommes de terre fourragères; e) plantes fourragères. 2) Zones subtropicales : $f$ ) niébés et haricots; g) carthame; $h$ ) riz pluvial; i) sorgho blanc; j) manguier; k) litchi. 3) Zones de climat aride andin : I) palmier dattier; $m$ ) pistachier; n)jojoba; o) gayule; $p$ ) plantes aromatiques et médicinales. 4) Patagonie andine : cultures diverses (q). 5) Elevages : (r) moutons; (s) abeilles; (t) autres élevages. 


\section{L'érosion éolienne}

Elle est également importante, surtout dans les zones à climat semi-aride à l'ouest de la Pampa, et en tous cas sur sols sableux.

\section{Le mode d'exploitation actuel des élevages bovin et ovin}

Il est étroitement corrélé à la désertification dans de vastes zones arides et semi-arides du pays. Des milliers de kilomètres carrés de terres arables disparaissent chaque année : ils ne sont plus cultivables, et parfois à peine pâturables (Fecic-Prosa, 1988).

\section{Les méthodes d'irrigation}

Elles sont souvent archaïques : l'efficacité de l'eau est faible, et les pertes importantes. De gros efforts sont entrepris pour y remédier, mais le marasme lié au bas niveau des prix agricoles interdit tout changement rapide. La situation est pourtant préoccupante : des dizaines de milliers d'hectares sont déjà salinisés, voire perdus pour la culture, dans la plupart des périmètres d'irrigation.

\section{Le drainage}

II est le plus souvent inexistant : on a vu que dans la Pampa et le Chaco, pentes très faibles et engorgement des sols créent souvent des nappes d'eau en surface. Ces phénomènes sont de règle après chaque épisode pluvieux important : plus de 300000 ha de terres agricoles sont situées en zone endoréique dans la seule province de Buenos Aires (Fecic-Prosa, 1988).

\section{Méthodes plus conservatives}

Certaines sont déjà connues, mais il reste à les vulgariser : non-culture, engrais verts, semis en lignes alternées de la culture dérobée d'été dans la culture principale d'hiver, etc. Elles limiteraient la durée d'exposition des sols nus au soleil et faciliteraient l'infiltration des pluies en réduisant la dégradation de leur structure : Panigatti et al
(1983) ont montré que des résidus de culture forment un mulch qui réduit de moitié l'amplitude thermique jour-nuit à $5 \mathrm{~cm}$ dans le sol; mais la couverture permanente des sols érodables par des prairies constitue la méthode la plus efficace de protection.

Le suivi conjoint du bilan hydrique décadaire, des températures, et de la phénologie des principales espèces prairiales

Ce suivi a permis d'établir en Nouvelle-Zélande un modèle d'analyse du développement de la biomasse prairiale qui paraît assez opérationnel dans ce pays (Maunder, 1978). II reste à le valider dans les conditions d'Argentine (Vinocur, 1989).

Il en va de même pour les modèles climatiques de prévision des rendements à appliquer aux grandes cultures (Ravelo et al, 1989; Travasso, 1990).

\section{Etudes phénologiques et bioclimatiques}

Des études simples devraient permettre de sélectionner des espèces, variétés ou cultivars mieux adaptés à chaque situation locale (Magrin, 1990), et d'améliorer notablement les productivités agricole et fourragère, sans surcharge financière pour les producteurs; de nombreux travaux de I'INTA le prouvent (comme notamment ceux de la station de Mercedes de Corrientes).

\section{QUELLES CULTURES ET QUELS ÉLEVAGES NOUVEAUX ?}

Afin de permettre au lecteur de se repérer, la figure 15 , localise les principales "cultures nouvelles" envisagées : les lettres cerclées sur la carte sont reprises dans les paragraphes correspondants du texte.

\section{Dans les zones tempérées humide et subhu- mide}

En culture d'hiver, quelques espèces, généralement déjà introduites, pourraient améliorer les 
systèmes de cultures actuels (Baldy, 1989; Gargiulo, 1988; Mercier, 1990).

\section{Les colzas oléagineux et fourragers (a)}

Ils devraient prendre dans le futur en Argentine une importance aussi grande qu'actuellement en Europe, au Canada, ou en Inde. Les variétés européennes et canadiennes actuelles sont dépourvues d'éléments éventuellement nocifs comme l'acide érucique. Elles paraissent climatiquement bien adaptées au sud du $35^{\circ} \mathrm{S}$ (fig 1, 3 et 4) : des essais conduits par l'université du Sud (Bahia Blanca) l'ont montré. Inversement, les essais dans des stations de I'INTA situées plus au nord ont prouvé le manque d'adaptation de ces espèces de climat tempéré froid à la zone subtropicale. Des essais seraient à poursuivre dans cette dernière zone avec des variétés indiennes, génétiquement différentes des européennes.

Colzas, moutardes et navettes fourragers sont à récolter à la floraison, pour éviter leur resemis dans les cultures suivantes.

\section{La betterave sucrière (b)}

Elle a été introduite dans la région de Pergamino dès la fin des années 1950 avec d'excellents rendements; des pressions politiques l'ont fait interdire car elle risquait de concurrencer la canne à sucre (Michajlkov et Juarez, 1964).

Des essais de betteraves fourragères poursuivis à Balcarce sur de petites surfaces démontrent l'intérêt de cette culture pour les sols salinisés de la dépression du Rio Salado (fig 8) (Gotz, communication personnelle) : la betterave a en effet un pouvoir intéressant d'absorption des sels de sodium.

Il a été prouvé (Gotz, communication personnelle) que les bovins peuvent consommer les racines in situ (aussi bien que les parties aériennes), ce qui supprime, dans un premier temps, le problème du stockage en silos, dans les zones où les producteurs ne sont pas équipés.

Carottes, navets, choux et choux-raves fourragers peuvent être utilisés de façon analogue; leurs durées de cycle très variées, leurs réactions différentes aux sols et aux conditions climatiques hivernales, font souhaiter leur introduction en stations expérimentales (afin de vérifier l'adaptation des variétés), puis en champs pilotes : ils permettraient l'amélioration de l'alimentation du bétail, pendant l'hiver, y compris des porcs, sans trop augmenter les coûts de production.

\section{Les lupins (c)}

C'est une autre source de diversification. Spontanés ou subspontanés dans diverses régions d'Argentine (Planchuelo et Ravelo, 1988), il faut introduire des variétés dépourvues de lupinine, et donc directement comestibles. Les travaux entrepris prouvent la bonne adéquation des lupins doux aux conditions climatiques, du nord de la Pampa au Nord de la Patagonie.

\section{Les pommes de terre fourragères (d)}

Cette culture, si développée en Europe du Nord (et en France) est ignorée des agriculteurs argentins. L'introduciton de variétés adaptées est à encourager dans le sud du pays (Patagonie), et aussi, accompagnée d'irrigation, dans les zones arides d'altitude du nord-ouest.

\section{Les graminées et légumineuses fourragères (e)}

Elles font l'objet de nombreux travaux de recherche, tant à I'INTA que dans les universités; la plupart des plantes fourragères des zones tempérées peuvent être introduites en Argentine avec le même succès que la luzerne. Diverses espèces fourragères autochtones sont d'un grand intérêt, mais exigent quelques efforts de sélection : la plupart des problèmes d'adaptation bioclimatique posés par l'introduction d'espèces disparaissent en sélectionnant des espèces autochtones.

\section{En zone sub-tropicale}

D'assez nombreuses cultures sont à retenir en climat sub-tropical :

\section{Les niébés et haricots (f)}

Le cow-pea (ou niébé, Vigna unguiculata) compte des centaines de variétés, (dont les cycles de végétation varient de 65 à et plus $250 \mathrm{j}$ et plus), adaptées à des climats tropicaux secs aussi bien qu'humides et plus ou moins chauds. Certains cultivars sont typiquement fourragers, d'autres produisent des haricots très appréciés, en Afrique comme au Brésil. Très riche en pro- 
téines, ce protéagineux est encore mal connu en dehors de ses zones d'origine.

L'espèce est très sensible aux bruches et autres insectes du grain : les introductions doivent prendre en compte la résistance à ces parasites.

L'Argentine est un grand producteur de haricots en grains (Phaseolus vulgaris), pour sa propre consommation et pour l'exportation. Le marché brésilien intéresse particulièrement les producteurs; mais les achats brésiliens sont étroitement liés aux possibilités financières, au niveau de production national, et plus encore aux nécessités politiques de l'année.

Les importateurs européens s'intéressent aux haricots argentins; malheureusement les variétés proposées sont souvent inadaptées, en raison du choix par les producteurs de cultivars qui répondent à leur goût plutôt qu'à celui des acheteurs. Le tout se traduit par des ventes à bas prix. Une politique tournée vers les consommateurs étrangers permettrait d'élargir et d'accroître notablement les ventes.

\section{Le carthame (Carthamus spp.) (g)}

II était largement cultivé il y a quelques années en Argentine; assez résistant à la sécheresse, il offre une possibilité de rotation dans les zones cotonnières. Des cultivars inermes à bons rendement et teneur en huile existent; les tourteaux peuvent eux aussi être mieux valorisés, en séparant les amandons des épicarpes.

\section{Le riz pluvial (Oryza japonica) (h)}

II représente $85 \%$ des surfaces plantées en riz au Brésil et près de $100 \%$ en Afrique tropicale. Les variétés actuelles sont souvent d'excellente qualité gustative et culinaire. Le marché se développera certainement dans l'avenir : ces variétés sont moins coûteuses à produire, et plus économes en eau. Des essais de la station de I'INTA de Misiones l'ont prouvé (résultats non publiés). Peu de recherches portent sur cette culture en Argentine. De vastes zones irrigables, mais non submersibles pourraient avoir des rendements comparables à ceux des maìs, sans exiger autant d'investissements que les rizières de type asiatique actuelles.

\section{Le sorgho blanc (Sorghum) (i)}

Les sorghos argentins sont essentiellement fourragers. Cette culture, très développée dans les régions soudano-sahéliennes d'Afrique, en Inde et en Chine, constitue, dans beaucoup de ces pays, la base de l'alimentation. Des variétés destinées à l'alimentation humaine, mais adaptées aux conditions climatiques locales d'Argentine, permettraient de rechercher des marchés nouveaux.

\section{Le manguier (Mangifera indica) (j)}

Il s'est naturalisé des provinces du Nord. Les arbres ont été introduits du Brésil sans tenir compte de leur sensibilité au froid. Les fruits sont de qualité gustative variable. Cette culture n'a pas actuellement d'importance économique : la plupart des mangues consommées en Argentine sont importées. Des plantations de variétés à maturation décalée, résistantes au froid (qui existent dans les collections mondiales), diversifieraient les productions des 6 provinces de Misiones, Corrientes, Formosa, Chaco, Salta et Jujuy. Des exportations pourraient être envisagées de décembre à mars vers l'Europe et l'Amérique du Nord.

\section{Les litchi et longane (nephelium litchi, $\mathbf{N}$ longan) (k)}

lis sont essentiellement cultivés dans leurs pays d'origine (Chine, Malaisie, Indonésie, etc) : ils ont des besoins en froid non négligeables pour fleurir. II existe peu de zones favorables dans le monde : le Nord de l'Argentine en est une. Une introduction récente de litchis au nord-est de la province de Corrientes a supporté les froids exceptionnels de $1988\left(-5^{\circ} \mathrm{C}\right)$.

Un vaste marché, à contre-saison de la Chine, est à développer dans l'hémisphère nord, analogue à celui qui a été créé pour le kiwi. Des plantations sont à réaliser afin de pouvoir développer les ventes sur les marchés européen et nord-américain.

\section{En zones de climats arides andins}

D'assez nombreuses cultures ont été essayées, ou sont en cours d'introduction. On peut citer :

\section{Le palmier dattier (Phoenix dactylifera) (I)}

Quelques vergers existent en Argentine dans les provinces de la Rioja, San Luis et Catamarca. Ils se sont développés à partir de noyaux, sans 
qu'aucun effort de sélection des clones les plus intéressants n'ait été entrepris : il y a donc autant de variétés que de plantes; mais ils prouvent l'adaptation climatique et pédologique du dattier dans la région.

Les techniques actuelles de micropropagation permettraient d'introduire en Argentine les variétés les plus appréciées sur les marchés mondiaux (comme la Deglet-Nour). L'Argentine pourrait ainsi contribuer à pallier la pénurie chaque année plus grande de dattes de bonne qualité, due au développement du dessèchement des palmiers, ou bayoud, en Afrique du Nord.

\section{Le pistachier (Pistacia vera) (m)}

II a été introduit depuis longtemps dans la région de Buenos-Aires, où il n'a pas donné de résultats satisfaisants, pour des raisons climatiques évidentes. Très récemment introduit à Mendoza, il y prospère bien. Cette espèce est elle aussi fortement déficitaire au niveau mondial. Les vergers peuvent produire des récoltes normales, sans irrigation, avec des pluies d'été de $350 \mathrm{~mm}$.

En zones plus sèches, l'espèce nécessite quelques irrigations annuelles, pendant sa période active (de novembre à avril). II doit s'adapter jusqu'à 700-800 m d'altitude (voire plus dans les vallées Calchaquies). Cette espèce peut assurer des revenus comparables à ceux des autres arbres fruitiers, avec moins de travail.

\section{Le jojoba (Simmondsia sinensis) (n)}

Son irrigation paraît peu intéressante, sauf peutêtre les 2 premières années, quand la chose est possible sur un plan économique. II donne de bons résultats dans des zones arides ou subarides à climat continental, fortes amplitudes thermiques jour-nuit, 150 à $400 \mathrm{~mm}$ de pluies à dominante estivale, étés chauds et hivers frais, mais peu gélifs (Ayerza, 1984).

\section{La culture du guayule (Parthenium argentatum) (0)}

Elle a été envisagée aussi, pour en extraire son caoutchouc. Mais il faudrait que le prix du pétrole augmente beaucoup pour que cette culture puisse devenir rentable, par rapport aux caoutchoucs artificiels... (Ayerza et Bengtson, 1986).

L'introduction du pyrèthre (Pyrethrum sp) peut être intéressante dans les zones semi-arides d'altitude : cette culture, originaire des mon- tagnes dalmates, réussit mal en plaine car son taux de pyréthrine y est faible.

Le quinoa (chénopodiacée originaire des régions andines) réussit bien; encore faudrait-il que des échanges commerciaux existent pour cette espèce.

\section{Plantes aromatiques et médicinales ( $p$ )}

De nombreuses espèces sont cultivées dans tout le pays. La recherche de génotypes riches en principes actifs, de méthodes de cultures permettant de les utiliser pour la protection des sols contre l'érosion, la recherche de débouchés, et le développement d'une industrie d'extraction modernisée ouvriraient au pays des marchés qu'ont su se ménager des pays comme la Bulgarie ou la Roumanie.

\section{En Patagonie andine}

Les fonds de vallées humides de la Patagonie andine sont encore peu exploités, faute de moyens de transport bon marché, et en raison des distances considérables jusqu'aux marchés de consommation. Des centaines de milliers d'hectares y jouissent d'un climat quasi méditerranéen en été, avec des hivers frais ou froids. Diverses cultures, peu développées, voire importées actuellement, pourraient y trouver place.

Le gouvernement provincial améliore le réseau routier et la desserte aérienne de la région d'el Bolsón afin de faciliter les exportations des productions agricoles (tant vers le reste de l'Argentine que vers l'étranger) de cette région au climat très particulier. Chaque vallée (que son débouché soit sur l'Atlantique ou le Pacifique) est très isolée des voisines par des chaînons montagneux, ou, à l'est, par la steppe. Elles constituent donc les isolats que recherchent les semenciers pour assurer la multiplication de plantes horticoles ou fourragères.

La région pourra ainsi produire plus de houblon, et aussi tous les petits fruits rouges de confiturerie, dans des conditions climatiques très favorables.

\section{Quels élevages nouveaux envisager?}

Les services argentins de l'agriculture cherchent à diversifier les élevages. Plusieurs espèces sont à réenvisager, ou à réintroduire. On peut citer : 


\section{Les moutons à laine et à viande}

À la fin du siècle passé, jusqu'à $75.10^{6}$ moutons ont exploité les pâturages : toute la Pampa, la Mésopotamie et la Patagonie étaient plus ou moins complètement occupées par des troupeaux destinés essentiellement à la production lainière.

Le développement progressif de l'élevage bovin à viande moderne, du fait de l'ouverture de marchés sans cesse plus demandeurs font que les moutons ont été progressivement confinés aux zones les plus marginales: Patagonie, dépression du Rio Salado dans la province de Buenos Aires, et quelques zones en Entre Rios et à Corrientes. La réduction du troupeau est énorme: il ne reste que $22.10^{6}$ têtes de nos jours.

La production de viande pour l'exportation est actuellement quasi nulle : les éleveurs maintiennent à peine leur cheptel. En plus de vieilles brebis, seuls quelques centaines de milliers d'agneaux mâles peuvent être vendus. Et les frais de transport à partir de zones éloignées dépassent souvent le prix de vente des animaux, d'où un effet d'entraînement négatif.

Une politique plus active d'encouragement à la production d'agneaux, d'antenais et de moutons de races à viande permettrait de proposer aux marchés internationaux quelques millions d'animaux sur pied et de carcasses par an, comme le font l'Australie et la Nouvelle-Zélande : la recherche de marchés exige de prospecter activement les pays arabes, grands demandeurs d'animaux mâles vivants d'un an, notamment pour l'Aid el Kebir.

En ce qui concerne la production de laine, des travaux de I'INTA ont mis en évidence qu'il faut améliorer les races les plus utilisées actuellement par des croisements d'absorption. Trop de laine d'origine argentine se vendent à bas prix, en raison de fibres trop grossières, alors qu'elle proviennent de régions favorables à l'élevage de races à laine fine.

\section{Les abeilles}

L'Argentine est le $5^{\mathrm{e}}$ exportateur mondial de miel, derrière la Chine et le Mexique notamment. Une analyse des capacités de production montre qu'elle pourrait doubler ou tripler. Les producteurs n'ont pas été incités jusqu'à présent à présenter leur production de façon attrayante sur les marchés importateurs : les miels sont simple- ment classés en blancs et colorés, sans indication d'origine, et l'exportateur principal les achète toujours au plus bas prix $(0,6 \mathrm{US} \$ / \mathrm{kg}$ au départ de Buenos Aires), c'est à dire au prix du sucre brut. Une réglementation nationale mieux adaptée permettrait aux apiculteurs de doubler leur production, et de dépasser le prix de 1 US\$/ $\mathrm{kg}$.

\section{Autres élevages}

Des élevages industriels d'oies pourraient valoriser mieux les productions de céréales et ouvrir des exportations. Les lapins sont surtout exploités pour la production de poils angora et leur chair est peu appréciée; des croisements industriels avec des races de chair pourraient améliorer la qualité des viandes, sans perdre la production de poil des mères. Un grand nombre d'espèces de la faune sauvage sont envisagées par les services de recherche ou de développement, parmi lesquelles les visons, les ragondins, et d'autre encore (Coscia, communication personnelle).

\section{CONCLUSIONS}

L'Argentine, vaste pays aux climats et aux sols variés, mais à la population peu nombreuse et très mal répartie, a un potentiel considérable de production agricole à mettre à la disposition du reste du monde. Mais, au lieu de se contenter de proposer des produits traditionnels, généralement de moins en moins compétitifs, elle doit réorienter ses productions vers de nouveaux marchés. Ainsi, le maïs ou le lin oléagineux sont concurrencés dans le monde entier par l'amélioration des rendements, dans le cas du maïs, ou par l'apparition de produits industriels nouveaux, qui ont rendu l'huile de lin moins concurrentielle.

Par contre, des céréales de bonne qualité comme les blés tendres et durs conserveront probablement toujours un marché, en raison de leur coût de production élevé en zones tropicales et polaires. II peut en aller de même de cultures comme le cotonnier : les nouveaux cultivars sans gossypol (glandless) permettent d'utiliser ses tourteaux en alimentation animale et humaine directe, et augmentent leur valeur ajoutée.

La production bovine mondiale est potentiellement déficitaire à moyen terme; des pays comme le Brésil atteignent des niveaux d'expor- 
tation impensables il y a peu d'années; mais cette production se fait au détriment de la conservation du milieu naturel : qu'une conscience un peu plus aigüe du problème s'y fasse jour, et ils ne chercheront plus que l'autosuffisance.

Un élément particulièrement méconnu reste la production ovine : l'Argentine fut un grand réservoir de moutons jusqu'au milieu du siècle; cet élevage est passé de 50 à environ $22.10^{6}$ têtes en 30 ans. Le regain d'intérêt porté dans le monde entier aux tissus naturels (laine, coton, mais aussi lin) fait bien augurer de l'avenir : l'introduction des systèmes de tonte australiens ou néozélandais facilite cette opération consommatrice d'une main d'œuvre rare, ce qui peut redonner vie à cette production; il faudrait faciliter aussi le développement d'une industrie dynamique, plutôt que de laisser partir la laine brute.

Des productions apparemment marginales comme l'ail ou le miel (à condition d'améliorer les conditions d'exportation de ce dernier produit) peuvent rapporter autant à l'économie argentine que des produits de faible valeur unitaire, mais de grosse production. II est difficile de faire admettre cette idée aux grands producteurs, qui vivent encore assez bien, sans trop d'efforts, des productions traditionnelles. Mais les temps changent, et à plus ou moins court terme, des décisions seront à prendre. II serait préférable de les prendre calmement plutôt que d'y être contraint par la pression d'une mévente durable.

La diversification des productions agricoles représente une des voies les plus sûres de modernisation de l'Argentine (Gargiulo, 1988; Mercier, 1990). Nous avons montré que la plupart de ces productions ne sont pas nouvelles : elles existent déjà à petite échelle, mais n'ont fait l'objet ni d'études de marché, ni même souvent de plantations suffisamment étendues pour que ces études soient envisageables dans l'immédiat.

Elle exige parallèlement d'industrialiser le traitement des produits. Sans un effort dans ce sens, l'Argentine restera un producteur de produits non transformés : l'exemple de pays analogues montre que, sans le développement d'industries de transformation, qui agrègent une valeur ajoutée importante, le PBI per capita plafonne au mieux à 3000 US\$. L'Argentine peut faire mieux, au vu de l'ensemble de ressources humaines, agricoles et minières actuellement connues.

\section{RÉFÉRENCES}

Altuve de Garcia SM (1988) Especies forrajeras subtropicales : evaluación de semillas. Informe de investigación 1986-87. EEA Mercedes (Corrientes) 98-101

Ayerza R (1984) La Jojoba. Hemisferio sur Buenos Aires, $224 \mathrm{p}$

Ayerza R, Bengtson (1986) Guayule. Sub comité assoc arido subtrop andino $51 \mathrm{p}$

Baldy CM (1989) Agrometeorologia y desarrollo en Argentina de cultivos o rubros nuevos. INTA Castelar, Agua y Clima. Publicación $N^{\circ} 31,44 p$

Ballare CL, Scopel AL, Ghersa CM, Sanchez RA (1987) The demography of Datura ferox $L$ in soybean crops. Weed Res 27, 91-102

Bortagaray LL (1988) Recursos naturales potenciales, parcialmente valorados : In: Roccatagliata. La Argentina, geografía general y los marcos regionales. Planeta, Buenos Aires 199-226

Bull Inf Econ Commerc Ambassade de France en Argentine, Nouvelle série, 1988-1989

Burgos JJ (1983) El clima en la producción de alimentos en America latina. Acta conf Clima America lat Caribe. OMM 632 158-184

Capitanelli RG (1988) Los ambientes naturales del Territorio argentino : In: Roccatagliata : La Argentina. Planeta Buenos Aires. 81-144

CIEF (1985) Distribucion regional y condiciones ecológicas de los eucaliptos cultivados en la Argentina CIEF, Benos Aires. Publ Tec N ${ }^{\circ} 1,19 p$

Conti HA, Santamaria JR (1987) Regimen de Iluvias y su probabilidad de ocurrencia en Castelar. INTACIRN-Agrometeorología. Publ N ${ }^{\circ} 21,10 p$

Coscia AA (1983) Segunda revolucion agricola en la región pampeana. Cadia Buenos Aires, $242 \mathrm{p}$

Daus FA (1987, 1988) Geografía de la Argentina. 1. Parte humana 171 p; 2. Parte Física y política 156 p; Editorial Estrada, Buenos Aires.

Defina AL (1973) Mapa nacional de los distritos agroclimáticos argentinos. IDIA $N^{\circ} 311,21-48$

Defina AL, Ravelo AC (1973) Climatología y fenología agrícolas. Eudeba, Buenos Aires, $281 \mathrm{p}$

Deybe D (1989) Politiques agricoles et érosion des sols en Argentine : une méthodologie pour leur analyse. Ms Sci, IAM-Montpellier, $91 \mathrm{p}$

FAO (1985) Agroclimatological data for Latin America and the Caribbean. FAO, Plant production and protection series, $N^{\circ} 24500 \mathrm{p}$

Fecic-Prosa (1988) El deterioro del ambiente en la Argentina. Centro para la promocion de la conservacion del suelo y del agua (Prosa). Fecic Buenos Aires $497 \mathrm{p}$

Flichman G (1986) La renta del suelo y el desarrollo agrario argentino. Buenos Aires, Siglo XXI $242 \mathrm{p}$ 
Flichman G, Deybe D (1987) Alternativas tecnológicas y politica agropecuaria. La producción de granos en la regíon pampeana. Buenos Aires, IICA 66 p

Frere M, Popov G (1979) Surveillance agrométéorologique pour la prévision des récoltes. FAO, Div Produc végét Prot, $\mathrm{N}^{\circ} 17,64 \mathrm{p}$

Gargiulo GR (1988) Informe final, Proyecto piloto de inovacion en agroindustria exportadora. $\mathrm{T} 1 \mathrm{Secr}$ Cienc Tecnica Buenos Aires, $249 \mathrm{p}$

Hall AJ, Rebella CM, Culot JP (1988) Field crop systems of the Pampas. Dactylographie $54 \mathrm{p}$

Magrin GO (1990) Etude des causes climatiques et physiologiques influant sur le rendement du Blé. Thèse Dr Ingénieur, ENSA-Montpellier, $160 \mathrm{p}$

Maunder WJ (1978) Forecasting pastoral production; the use and value of weather base forescasts and the implications to the transportation industry and the nation. Proc Symp Meteor Transport. N Ecolo Meteor Service 107-126

Mercier H (1990) El campo: la fuente para el desarrollo de una vigorosa industria química argentina. (Document ronéoté, Service commercial, Ambassade de France en Argentine) $21 p$

Michajlkov V, Juarez GA (1964) El cultivo de la remolacha azucarera en el Sudeste de la Provincia de Buenos Aires. IDIA-INTA 203, 15-32

Moscardi ER (1987) Bases para la conformación de los nucleos zonales de experimentación adaptativa $y$ transferencia del INTA. INTA, documento de trabajo $N^{\circ} 1$, Ser Experim adaptativa, $9 p$

Musto JC (1979) La degradación de los suelos de la República Argentina. Publ. 67, CIRN-INTA Castelar, Buenos Aires. $12 \mathrm{p}$

Panigatti JL, Perez M de C, Mossetti M (1983) Evolución de la temperatura del suelo: I Influencia de la cobertura; II Influencia del sombreado; III Influencia de la humedad. INTA-Rafaela, Misc 15, 16, $17: 35$ $+29+29 p$

Perego JL (1988) Colección in vivo de las especies componentes de la pradera natural en el área de
Mercedes (Corrientes). P 42. INTA - Informes de investigación 1986-87. EEA Mercedes (Corrientes)

Planchuelo de Ravelo AM, Ravelo AC (1988) Lupinos. Un cultivo con futuro. Bol div Secyt-Cordoba $21 \mathrm{p}$

Ravelo AC, Planchuelo de Ravelo A (1989) Calibración de un modelo fisiologico de rendimiento para arroz. IV reunión Argentina de Agrometeorología, Rio Cuarto. 11-19

Roccatagliata JA (Coordinador). (1988) La Argentina. Geografía general y los marcos regionales. Planeta. Buenos Aires, $783 \mathrm{p}$

de Rojas AC, Conde AA (1980) Determinación del índice de erosividad de las lluvias (segunda aproximación) : IX Reunion argentina de la Ciencia del Suelo, Paraná, 873-880

de Rojas AC, Conde AA, Moresco RF (1976) Determinación del índice de erosividad de lluvias para algunas localidades de Entre-Rios y Santa Fé. IDIA Suppl 33, 714-717

Saenz Quesada M (1980) Los Estancieros. Editorial de Belgrano, Buenos Aires, $339 \mathrm{p}$

Scotta ES, Nani LA, Conde AA, Rojas AC de Castaneira H, Paparotti O (1986) Manual de sistematización de tierras para control de erosión hidrica y aguas superficiales excedentes. INTA Paraná, Ser didáctica 17,51 $p$

Sociedad Rural Argentina (1989) Memoria anual de informe. T. CXXIII, Buenos Aires, $250 \mathrm{p}$

Suero E, Garay AF (1978) Estado estructural del horizonte superficial de suelos brunizem del SE. Bonaerense. II. Modificaciones producidas por el manejo. VIII Reunion arg. Ciencia del Suelo, Buenos Aires, 7-8

Travasso MI (1990) Etude des facteurs agroclimatiques limitant les rendements du blé dans la province de Buenos Aires. Thèse, Univ Paris-Orsay, $120 \mathrm{p}$

Vinocur M (1989) Desarrollo y evaluación de un modelo agrometerorológico para pasturas. In: IV Reunion arg. Agrometeorologia, Rio Cuarto, 231-235 